\title{
Neddylation-dependent protein degradation is a nexus between synaptic insulin resistance, neuroinflammation and Alzheimer's disease
}

\author{
Alessandro Dario Confettura ${ }^{1 \dagger}$, Eleonora Cuboni ${ }^{1 \dagger}$, Mohamed Rafeet Ammar $^{1}$, Shaobo Jia ${ }^{2}$, \\ Guilherme M. Gomes ${ }^{1,3}$, PingAn Yuanxiang ${ }^{1}$, Rajeev Raman ${ }^{1}$, Tingting Li ${ }^{4}$, Katarzyna M. Grochowska ${ }^{1,5}$, \\ Robert Ahrends ${ }^{4,6}$, Anna Karpova ${ }^{1,3}$, Alexander Dityatev ${ }^{2,3,7}$ and Michael R. Kreutz ${ }^{1,2,3,5^{*}}$ (i)
}

\begin{abstract}
Background: The metabolic syndrome is a consequence of modern lifestyle that causes synaptic insulin resistance and cognitive deficits and that in interaction with a high amyloid load is an important risk factor for Alzheimer's disease. It has been proposed that neuroinflammation might be an intervening variable, but the underlying mechanisms are currently unknown.

Methods: We utilized primary neurons to induce synaptic insulin resistance as well as a mouse model of high-risk aging that includes a high amyloid load, neuroinflammation, and diet-induced obesity to test hypotheses on underlying mechanisms.

Results: We found that neddylation and subsequent activation of cullin-RING ligase complexes induced synaptic insulin resistance through ubiquitylation and degradation of the insulin-receptor substrate IRS1 that organizes synaptic insulin signaling. Accordingly, inhibition of neddylation preserved synaptic insulin signaling and rescued memory deficits in mice with a high amyloid load, which were fed with a 'western diet'.

Conclusions: Collectively, the data suggest that neddylation and degradation of the insulin-receptor substrate is a nodal point that links high amyloid load, neuroinflammation, and synaptic insulin resistance to cognitive decline and impaired synaptic plasticity in high-risk aging.
\end{abstract}

Keywords: Metabolic syndrome, Alzheimer's disease, Neddylation, Cullins, MLN-4924, Insulin, IRS1, Amyloid- $\beta$, TNFa

\section{Background}

Modern lifestyle has led to a sharp increase in the elderly population and a growing prevalence of metabolic dysfunction. More than 1.4 billion adults worldwide are

\footnotetext{
*Correspondence: michael.kreutz@lin-magdeburg.de

${ }^{\dagger}$ Alessandro Dario Confettura and Eleonora Cuboni contributed equally to this work

${ }^{1}$ RG Neuroplasticity, Leibniz-Institute for Neurobiology,

39118 Magdeburg, Germany

Full list of author information is available at the end of the article
}

overweight, with a prevalence of obesity of $20 \%$ in Organisation for Economic Co-operation and Development countries and almost $40 \%$ in the USA [1]. The metabolic syndrome (MetS), which is characterized by overweight, insulin resistance, high glucose levels and hypertension, has become a major threat to healthy living and active aging. Of note in this regard, the MetS is also associated with a higher risk of late-onset Alzheimer's disease (LOAD) [2-6]. Individuals diagnosed with MetS show a greater risk of developing cognitive decline later 
in life [3, 7-9] and LOAD patients tend to have an even poorer prognosis when MetS is diagnosed as well [3, 10, 11]. Accordingly, early epidemiological studies suggested that a reduction of prevalence of MetS symptoms by $25 \%$ would reduce the incidence of LOAD in a population with high amyloid load by $20 \%$ [12].

The MetS has been associated with impaired performance in different cognitive domains [8], some of which are associated with the hippocampus-dependent learning and memory $[13,14]$. Accordingly, synaptic insulin resistance (IR) in the hippocampus is one of the hallmarks of cognitive decline in MetS [13, 15, 16]. It has been suggested that IR and amyloid- $\beta$ (A $\beta)$ pathology interact functionally in Alzheimer's disease (AD) [10, 1719] and that their interaction might cause worsening of AD symptoms. However, this notion is based on several unknowns. The underpinnings of the molecular interplay between IR and $A \beta$ pathology are, for instance, not well understood, in part because the topology and regulation of synaptic insulin signaling pathways are not well investigated. Along these lines, the mechanisms underlying synaptic IR are not entirely clear yet.

Numerous studies have demonstrated that chronic neuroinflammation is prominently present in the brains of $\mathrm{AD}$ patients [20-22] and previous work has proposed a link between elevated levels of proinflammatory cytokines and $A \beta$-induced synaptic dysfunction [23]. In particular, tumor necrosis factor- $\alpha$ (TNF $\alpha)$ has deleterious effects on the plasticity and integrity of spine synapses [23]. A causal link of $A \beta$-induced synaptic dysfunction to neuroinflammatory processes is very likely since published data suggest that a 'western diet' promotes inflammatory processes in the brain very similar to those described for $A \beta$ pathology $[11,24,25]$. Collectively, the evidence points to a pathological triad consisting of synaptic IR, chronic neuroinflammation and $A \beta$ deposition as a hallmark for high-risk aging. In the present study, we identified a nodal point of interaction of all three conditions that might be used as a target for intervention. To that end, we established in vitro and in vivo models to examine interactions occurring at the prodromal phase of LOAD, including a transgenic mouse model of high cerebral amyloid levels as a predisposing environment.

\section{Methods}

\section{Neuronal cell culture}

Rat neuronal primary cultures were prepared as described previously [26]. Hippocampal or cortical neurons at 21-days in vitro (DIV) were treated for $24 \mathrm{~h}$ with $100 \mathrm{nM}$ insulin, $10 \mathrm{ng} / \mathrm{ml} \mathrm{TNF} \alpha$, or a combination of both to induce IR in vitro. Glial release of TNF $\alpha$ induces neuroinflammation [23]. Therefore during the preparation of neuronal primary culture, the addition of Ara-c (cytosine $\beta-D$-arabinofluranoside), a suppressor of glial proliferation, was omitted. Before application, half of the conditioned Neurobasal Medium (NB, Gibco, Gaithersburg, MD) was replaced with fresh serum-free NB medium. To assess responsiveness to insulin, cell were washed with conditioned NB medium for $1 \mathrm{~h}$ and either $100 \mathrm{nM}$ insulin or vehicle was applied for $15 \mathrm{~min}$.

\section{TBA2.1 mice and MetS}

Mice were housed in groups of up to 4 in individually ventilated cages (IVCs, Green line system, Tecniplast, Lugano, Switzerland) under controlled environmental conditions $\left(22 \pm 2{ }^{\circ} \mathrm{C}, 55 \% \pm 10 \%\right.$ humidity, $12 \mathrm{~h}$ light/ dark cycle, with lights on at 06:00). Animals had free access to food and water. Male wild-type (WT, $+/+$ ) and heterozygous $(+/ \mathrm{Tg})$ TBA2.1 mice [27] were fed with normal chow until the age of 8-9 weeks. After this period, they were fed with either a regular diet (RD) or a high-fat/high-calorie chow (High-fat diet [HFD], Ssniff \#E15126-34, Soest, Germany). Mice fed with HFD were selected for further experiments when they reached a $70 \%$ body weight increase, which took on average 4-5 months. Mice used in the experiments were 6-8 months old.

\section{$A \beta 3(p E)-42$ oligomer and drug treatment}

A $33(\mathrm{pE})-42$ oligomers (Anaspec, \#AS-20,276; Fremont, CA) were prepared according to a previously established protocol [28]. The lyophilized peptide was dissolved in 1,1,1,3,3,3-hexafluoro-2-propanol (HFIP) to $0.5 \mathrm{mg} / \mathrm{ml}$ and the aliquots were stored at $-80{ }^{\circ} \mathrm{C}$. HFIP was evaporated for $24 \mathrm{~h}$ at room temperature. The peptide was dissolved in $0.1 \mathrm{M} \mathrm{NaOH}$, diluted in $\mathrm{NB}$ medium buffered with $0.1 \mathrm{M} \mathrm{HCl}$, and incubated for $24 \mathrm{~h}$. The oligomers were added directly to cultures at a final concentration of $500 \mathrm{nM}$ [24]. The neural precursor cell-expressed developmentally down-regulated gene 8 (NEDD8) inhibitor MLN-4924 (\#A-1139, Active Biochem, Hong Kong, China) was directly applied to the culture medium at a final concentration of $1 \mu \mathrm{M}$ [29]. MG-132 (\#M-1157, AG Scientific, San Diego, CA) was used in cell culture experiments at a final concentration of $20 \mu \mathrm{M}$.

\section{Expression constructs and Adeno-associated virus 9 (AAV9) infection}

Expression constructs are listed in Additional file 1: Table S1. Cortical neurons cultured in T-75 flasks (\#156499, Thermo Scientific, Freiburg im Breisgau, Germany) were infected at DIV10 with 10,000 vg/cell of AAV9 expressing either HA-NEDD8 or the HA tag alone for 14 days. Thereafter, neuronal cell lysates were used for 
tag-specific immunoprecipitation with anti-HA microbeads ( $\mu$ MACS $^{\text {TM }}$ HA Isolation Kit, \#130-091-122, Miltenyi Biotec, Bergisch Gladbach, Germany).

\section{Glucose tolerance test}

A small drop of blood $(<5 \mu \mathrm{l})$ was taken from the tail vein of the animals and placed on the test strip of the blood glucose meter Contour Next (Bayer, Leverkusen, Germany). Glucose in the blood measured after 6-h fastening was considered as the basal level $(t=0)$. Immediately after the first measurement, $D(+)$ glucose solution of $0.25 \mathrm{~g} / \mathrm{ml}$ was intraperitoneally injected into the animals at a final concentration of $1 \mathrm{~g} / \mathrm{kg}$. Blood glucose levels were measured at $15,30,60$ and $120 \min (t=15, t=30$, $\mathrm{t}=60$ and $\mathrm{t}=120$ ) postinjection.

\section{Enzyme-linked immunosorbent assays (ELISA)}

Animals were anesthetized with ketamine $(100 \mathrm{mg} / \mathrm{kg})$ and xylazine $(10 \mathrm{mg} / \mathrm{kg})$. Blood was collected directly from the heart ventricle. Following blood coagulation at room temperature, samples were centrifuged for $10 \mathrm{~min}$ at $1500 \mathrm{~g}$ and the blood serum was collected. Serum insulin levels were measured using a mouse insulin ELISA kit (\#EZRMI-13 K; Merck Millipore, Darmstadt, Germany). To determine the TNF $\alpha$ level in brain tissue, frozen cortices from WT and heterozygous TBA2.1 mice fed with either RD or HFD were homogenized in ice-cold PBS supplemented with protease inhibitor cocktail. After two freeze-thaw cycles, the homogenates were centrifuged for $5 \mathrm{~min}$ at $5000 \mathrm{~g}$ at $4{ }^{\circ} \mathrm{C}$. The supernatant was assayed immediately after isolation using a mouse TNF $\alpha$ ELISA kit (\#MHSTA50; R\&D Systems, Wiesbaden, Germany) according to the manufacturer's instruction.

\section{Behavioral experiments}

Novel location recognition and novel object recognition experiments were performed in a square arena $\left(50 \times 50 \times 50 \mathrm{~cm}^{3}\right)$ under mild light conditions as described previously [30]. The task consisted of 4 sessions: habituation, training, novel location recognition and novel object recognition. On the first day, the animals were habituated to the empty arena for $20 \mathrm{~min}$. The training session took place $24 \mathrm{~h}$ later where the mice were left free to explore for $20 \mathrm{~min}$ a pair of similar objects (made of plastic mounting bricks), positioned in the arena. Twenty-four hours later, one of the identical objects was moved to a new position, and mice were left for $20 \mathrm{~min}$ in the arena for exploration. After the last 24-h interval, a novel object recognition test was performed, in which a familiar object was replaced by a novel one and free exploration was observed for $20 \mathrm{~min}$. In studies of the effect of MLN-4924 in HFD-fed mice, the exploration time in all sessions was set to $10 \mathrm{~min}$. All four sessions were video-recorded, and behavior was analyzed offline using ANY-maze software (ANY-MazeTM Video Tracking System, version 4.50/4.99, Stoelting Co., Wood Dale, IL). Exploration was considered only when the animal touched or reached the objects with nose at a distance of less than $2 \mathrm{~cm}$. The time mice spent exploring the objects was recorded, and the discrimination index was calculated, taking into account the difference of time spent exploring the new and the familiar object locations $\left(\left(\mathrm{T}_{\text {new }}-\mathrm{T}_{\text {familiar }}\right) /\left(\mathrm{T}_{\text {new }}+\mathrm{T}_{\text {familiar }}\right) \times 100 \%\right)$. Chambers and objects were cleaned with $10 \%$ ethanol before and after each animal was tested.

\section{MLN-4924 administration in mice}

MLN-4924 was solubilized in DMSO at a concentration of $25 \mathrm{mg} / \mathrm{ml}$. To increase the solubility of MLN4924 in aqueous buffer, the solubilized drug was mixed with a solution of $10 \%$ non-toxic hydrophilic solubilizer 2-hydroxypropyl- $\beta$-cyclodestrin （\#12446-35-5; SigmaAldrich Chemie, Hamburg, Germany) to a final concentration of $0.5 \mathrm{mg} / \mathrm{ml}$ and sterile filtered. A dose of $2 \mathrm{mg} /$ $\mathrm{kg}$ of MLN-4924 or vehicle was injected intraperitoneally once a day for 14 days.

\section{Acute hippocampal slice preparation and electrophysiology}

Hippocampal slices from male WT $(+/+)$ and heterozygous TBA2.1 $(\mathrm{Tg})$ mice were prepared according to previously described protocols [28, 29]. Field excitatory postsynaptic potentials (fEPSPs) were recorded with glass capillary microelectrodes (3-5 M $\Omega$ ) filled with artificial cerebrospinal fluid (aCSF), amplified by an Extracellular Amplifier (EXT-02B, NPI electronic, Germany) and digitized at a sampling frequency of $5 \mathrm{kHz}$ by Digidata 1401plus AD/DA converter (CED, England). Stimulation strength was adjusted to $40 \%-50 \%$ (long-term depression, LTD) of the maximum fEPSP-slope values. A single stimulus with $0.1 \mathrm{~ms}$ width was applied every $30 \mathrm{~s}$ (at $0.0333 \mathrm{~Hz}$ ) and values were averaged every $3 \mathrm{~min}$. Following 30-min stable baseline recording, a low-frequency stimulus (900 stimuli at $1 \mathrm{~Hz}$ frequency) was applied for induction of LTD. For bath application of MLN-4924, the drug was solubilized in DMSO and diluted in aCSF at a final concentration of $1 \mu \mathrm{M}$. Following 10-min baseline recording, MLN-4924 or DMSO was applied $20 \mathrm{~min}$ before LTD induction and kept for the entire duration of recording.

\section{Immunoprecipitation of phosphatidylinositide 3-kinase $\gamma$ (PI3KY) and PI3KY ELISA}

PI3K $\gamma$ was immunoprecipitated either from cultured primary cortical neurons or hippocampi of TBA2.1 mice. Cultured cells were collected in $20 \mathrm{mM}$ Tris $-\mathrm{HCl}$, 
$\mathrm{pH}$ 7.4, $137 \mathrm{mM} \mathrm{NaCl}, 1 \mathrm{mM} \mathrm{CaCl}{ }_{2} 1 \mathrm{mM} \mathrm{MgCl}_{2}$, and $1 \mathrm{mM} \mathrm{Na}_{3} \mathrm{VO}_{4}$, and pelleted at $500 \mathrm{~g}$. Dissected mice hippocampi were snap-frozen in liquid nitrogen, mechanically homogenized using a pellet pestle motor (Kimble Kontes, Vineland, NJ) and pelleted at $500 \mathrm{~g}$. Both types of samples were lysed for $1 \mathrm{~h}$ in lysis buffer $(20 \mathrm{mM}$ Tris$\mathrm{HCl}, \mathrm{pH}$ 7.4, $137 \mathrm{mM} \mathrm{NaCl}, 1 \mathrm{mM} \mathrm{CaCl}{ }_{2} 1 \mathrm{mM} \mathrm{MgCl}$, $1 \mathrm{mM} \mathrm{Na}_{3} \mathrm{VO}_{4}, 1 \% \mathrm{NP}-40,1 \mathrm{mM}$ PMSF) and then centrifuged at $14,000 \mathrm{~g}$ to sediment the insoluble material. The supernatant was incubated with $2 \mu \mathrm{g}$ of rabbit polyclonal anti-PI3KY antibody (\#5405; Cell Signaling Technology, Frankfurt, Germany) with gentle rotation for $1 \mathrm{~h}$ at $4{ }^{\circ} \mathrm{C}$. Secondary antibody-bound dynabeads protein G (\#10003D; Thermo Fisher Scientific, Schwerte, Germany) was incubated with the lysate containing the primary antibody-bound $\mathrm{PI} 3 \mathrm{~K} \gamma$ for $1 \mathrm{~h}$ at $4{ }^{\circ} \mathrm{C}$. The beads were collected with the use of DYNAL magnet (Invitrogen, Schwerte, Germany) and subsequently washed with the lysis buffer followed by wash buffer $(0.1 \mathrm{M}$ Tris- $\mathrm{HCl}$, $\left.\mathrm{pH} 7.4,5 \mathrm{mM} \mathrm{LiCl}, 1 \mathrm{mM} \mathrm{Na} \mathrm{VO}_{4}\right)$, TNE buffer $(0.1 \mathrm{M}$ Tris-HCl, pH 7.4, $5 \mathrm{mM} \mathrm{LiCl}, 1 \mathrm{mM} \mathrm{Na}_{3} \mathrm{VO}_{4}$ ) and an ELISA-reaction buffer $\left(20 \mathrm{mM}\right.$ Tris- $\mathrm{HCl}, 4 \mathrm{mM} \mathrm{MgCl}_{2}$, $10 \mathrm{mM} \mathrm{NaCl}$, ATP $150 \mu \mathrm{M})$. While still bound to the beads, $\mathrm{PI} 3 \mathrm{~K} \gamma$ reaction was set up by adding the reaction buffer supplemented with $10 \mu \mathrm{M}$ of $\mathrm{PI}(3,4) \mathrm{P}_{2}$ and incubation at $37{ }^{\circ} \mathrm{C}$ for $2 \mathrm{~h}$. In the negative control samples, $10 \mathrm{nM}$ of AS-605240 was added to inhibit PI3K $\gamma$ activity. The kinase reaction was stopped using the kinase stop solution (reaction buffer supplemented with $4 \mathrm{mM}$ EDTA). Reaction buffer containing the product of the enzymatic reaction phosphatidylinositol $(3,4,5)$-triphosphate $\left(\mathrm{PI}(3,4,5) \mathrm{P}_{3}\right)$ was collected and used for a competitive ELISA (PI3-Kinase Activity ELISA: Pico, \#K-1000S, Echelon Biosciences, Göttingen, Germany) according to the manufacturer's instructions. Thereafter, PI3K $\gamma$ was extracted from the beads using $2 \times$ SDS buffer and used for immunoblotting.

\section{Synaptosome preparation}

Synaptosomes were prepared from mouse cortices or primary rat cortical culture (21 DIV) according to previously published protocols [31,32]. The cortex from mice was used in toto. To assess synaptic responsiveness to insulin, isolated synaptosomes from $+/+$ and $+/ \mathrm{Tg}$ TBA2.1 mice on RD or HFD were stimulated with $100 \mathrm{nM}$ of insulin or vehicle for $10 \mathrm{~min}$ at $37^{\circ} \mathrm{C}$. The reaction was performed in HEPES-buffered Krebs-like buffer (HBK, containing $308 \mathrm{mM} \mathrm{NaCl}, 308 \mathrm{mM} \mathrm{KCl}, 154 \mathrm{mM} \mathrm{MgSO}_{4}$, $1 \mathrm{M} \mathrm{CaCl}_{2}, 100 \mathrm{mM} \mathrm{Na} \mathrm{HPO}_{4}, 87 \mathrm{mM}$ HEPES/Tris, $\mathrm{pH}$ 7.4, $0.48 \mathrm{~g} D(+)$-glucose) supplied with $8 \mathrm{mM}$ of ATP (\#A2383; Sigma-Aldrich Chemie, Hamburg, Germany).
Synaptosomes were centrifuged at 10,000 $\mathrm{g}$, washed twice with fresh buffer and finally lysed in $2 \times$ SDS buffer.

\section{Immunocytochemistry}

Neurons were fixed in $4 \%$ paraformaldehyde (PFA) at room temperature. After permeabilization with $0.1 \%$ Triton-X/PBS, cells were blocked in blocking buffer $(2 \%$ glycine, $2 \% \mathrm{BSA}, 0.2 \%$ gelatin and $50 \mathrm{mM} \mathrm{NH}_{4} \mathrm{Cl}$ ) and subsequently probed with primary and secondary antibodies (Additional file 1: Table S1) as described previously [32]. Coverslips were mounted with Mowiol (\# 17951500; Polysciences Inc., Hirschberg an der Bergstraße, Germany).

\section{Immunohistochemistry}

Mice were anaesthetized with isofluran (Baxter Deutschland $\mathrm{GmbH}$, Unterschleißheim, Germany) and then perfused with $0.9 \% \mathrm{NaCl}$ followed by fixation with $4 \%$ PFA in PBS. Brains were processed as described previously [33]. Briefly, slices were incubated in immunohistochemistry blocking buffer (10\% goat serum, $0.3 \%$ Triton-X 100 in PBS) and subsequently with primary antibody (Additional file 1: Table S1) diluted in blocking buffer. Hippocampi of both hemispheres from mouse brain sections were imaged on a SP5 CLSM system (Leica Mycroystem, Mannheim, Germany). Maximum projections of the scans, comprised of $5 \mathrm{z}$-stacks $(0.39 \mu \mathrm{m}$ z-step $)$, were created using Image J software (NIH, Bethesda, MD) for subsequent analysis. The region of interest (ROI) was defined by positioning a rectangular frame of $220 \times 300 \mu \mathrm{m}^{2}$ onto the pyramidal cell layer of CA1 adjacent to the fasciola cinereum at low-power magnification $(20 \times)$. Three to four brain sections from each animal were used for quantification and the number of positive cells for each marker (Iba1, GFAP, NeuN) was counted.

\section{Fluorescence microscopy and image analysis}

Image analysis was carried out using a Zeiss Axio Imager A2 fluorescent microscope (Zeiss, Jena, Germany) with Cool Snap EZ camera (Visitron System, Puchheim, Germany) and MetaMorph Imaging software (MDS Analytical Technologies, Ismaning, Germany). Up to 3 coverslips were treated individually and processed per group. For each coverslip, the same exposure time and intensity were taken among the different groups. After background subtraction, the fluorescence intensity of the immunosignal was measured along dendrites right after the first branching point using ImageJ software. The synaptic immunofluorescence intensities of pan-AKT and phospho-AKT were assessed in a region of $400 \mathrm{~nm} \times 400 \mathrm{~nm}$ square set 
by the mask generated based on synaptic marker Shank3. The Shank3 mask was created semi-automatically using OpenView software [34].

\section{Confocal laser scan microscopy}

Images were acquired using Leica SP8 TCS STED 3X confocal microscopy, equipped with a pulsed White Laser (WLL) and a diode $405 \mathrm{~nm}$ laser. To quantify changes of pAKT and AKT in the spines, dendrites were scanned sequentially with detection of Alexa fluorophore (AF) 488 for MAP2 or GFP, AF 568 and AF 633 for Shank3. The optical sections were acquired along $Z$-axis with $0.27-\mu \mathrm{m} \mathrm{Z}$ resolution. After background subtraction, the fluorescent intensity was measured within ROI defined by Shank3 mask using ImageJ software.

\section{Heterologous co-immunoprecipitation, pull-down assays and immunoblotting}

Human embryonic kidney-293-T (HEK293T) cells were transfected using published protocols [32] and heterologous co-immunoprecipitation was performed as described previously [26]. For insulin receptor substrate 1 (IRS1) ubiquitination analysis, cells were preincubated overnight with MLN-4924 $(1 \mu \mathrm{M})$ or vehicle. They were then harvested in ice-cold PBS supplemented with protease inhibitor cocktail. For pull-down assay, cells were pelleted and lysed in RIPA buffer $(50 \mathrm{mM}$ Tris- $\mathrm{HCl}, \mathrm{pH}$ 8.0, $150 \mathrm{mM} \mathrm{NaCl}, 1 \% \mathrm{NP} 40,0.5 \%$ Na-deoxycholate, $0.1 \%$ SDS) containing protease inhibitor cocktail and the de-ubiquitination inhibitor PR-619 (\#662141; SigmaAldrich, Hamburg, Germany). Following sonication and centrifugation for $10 \mathrm{~min}$ at $14,000 \mathrm{~g}$, the supernatant was incubated with $20 \mu \mathrm{l}$ of Chitin resin $(\#$ S6651L; New England Biolabs, Frankfurt am Main, Germany) while rotating for $2 \mathrm{~h}$ at $4{ }^{\circ} \mathrm{C}$. The lysate was then transferred to BioSpin Chromotographic columns (\#732-6204; Bio-Rad, Feldkirchen, Germany) and washed with RIPA buffer (50 mM Tris- $\mathrm{HCl}, \mathrm{pH}$ 8.0, $500 \mathrm{mM} \mathrm{NaCl}, 1 \% \mathrm{NP} 40$, $0.5 \%$ Na-deoxycholate, $0.1 \%$ SDS). Protein complexes were eluted with $2 \times$ SDS buffer. Both $20 \mu \mathrm{l}$ of input and the eluate were loaded onto SDS-PAGE gradient gels as described previously [32]. Images were acquired using Intas ECL Chemocam Imager (Li-cor, Bad Homburg vor der Höhe, Germany). Protein band intensities were measured using Gel Analyzer plugin ImageJ software $(\mathrm{NIH}$, Bethesda, USA) and normalized to the loading control.

\section{Statistics}

Statistical analysis was carried out with GraphPad Prism software (GraphPad software Inc., San Diego, CA). Data are presented as mean \pm SEM. Student's $t$-test (two experimental groups) or one-way ANOVA followed by
Tukey's multiple comparison test was used for comparison as denoted in figure legends. For biochemical and behavioral analysis, a two-way ANOVA was employed followed by Bonferroni's multiple comparison test. For LTD experiments, averages from 180 to 210 min after LTD induction were compared by two-way ANOVA followed by Bonferroni's multiple comparison test.

\section{Results}

\section{Induction of synaptic IR}

Studies on molecular mechanisms of synaptic IR are facilitated by simplistic models that still have enough complexity to allow for the generation and verification of hypotheses. In the first set of experiments, we therefore established an in vitro model of synaptic IR in neuronal primary cultures, which included 24-h bath application of insulin and TNF $\alpha$. Following the activation of TNF $\alpha$ receptor 1 , stress kinases such as c-Jun $\mathrm{N}$-terminal kinase (JNK) and ІкB kinase induce serine phosphorylation of IRS1 [35] and this has been strongly linked to IR and impaired insulin signaling in neurons [36]. In previous work, we found that the post-translationally modified pyroglutamatylated $A \beta 3(\mathrm{pE})-42$ is taken up by astrocytes and potently induces glial release of TNF $\alpha$ and thereby causes synaptic dysfunction [23]. $A \beta 3(\mathrm{pE})-42$ is prominent in $\mathrm{AD}$ [37-39] and known to seed highly toxic oligomers that trigger neuroinflammation and TNF $\alpha$ release [40]. Hence, the combination of insulin and TNF $\alpha$ administration should resemble to a certain degree the condition of HFD-induced prolonged exposure to insulin and $A \beta$-induced neuroinflammation. Cells were therefore incubated with $100 \mathrm{nM}$ insulin and $10 \mathrm{ng} / \mathrm{ml}$ TNF $\alpha$ for $24 \mathrm{~h}$ followed by acute stimulation with insulin for 15 min to test for insulin responsiveness (Fig. 1a). One of the hallmarks of IR in response to insulin stimulation in many cell types is the diminished phosphorylation of the insulin receptor (pInsR) and the serine/threonine protein kinase-B/AKT (pAKT) [41]. Quantitative immunoblotting revealed reduced $\mathrm{pInsR} / \mathrm{InsR}$ and $\mathrm{pAKT} / \mathrm{AKT}$ ratios in response to 15-min insulin stimulation as a result of combined TNF $\alpha$ and insulin pretreatment, indicative of synaptic IR (Fig. 1b-d).

Stimulation of InsR activates insulin-receptor substrates, such as IRS1, by means of phosphorylation at specific tyrosine residues, resulting in activation of the downstream effectors PI3K and AKT. In contrast, phosphorylation of IRS1 at certain serine residues like Ser612 interrupts insulin signaling and renders the scaffold susceptible to degradation [42-46]. We indeed found an increased ratio of Ser612 phosphorylation as a result of overnight $\mathrm{TNF} \alpha /$ insulin treatment (Fig. 1b, e) that was caused by reduced IRS1 protein levels (Fig. 1b, f). Similarly, decreased protein levels of the less abundant family 
member IRS2 were observed (Additional file 1: Fig. S1a, b). Moreover, the total InsR level was also reduced, further indicating IR (Fig. 1b, g). Collectively, the results suggest that neuronal IR might develop as a consequence of an altered phosphorylation as well as protein degradation of IRS1 and IRS2.

We next isolated synaptosomes from cortical primary neurons treated with insulin and TNF $\alpha$ followed by acute insulin stimulation to test for insulin responsiveness (Fig. 1h). Reduced phosphorylation of AKT confirmed synaptic IR (Fig. 1i). In addition, immunocytochemistry of mature hippocampal primary neurons revealed reduced activation of AKT at postsynaptic sites (Fig. 1j, k) and no changes in total AKT fluorescence intensity (Additional file 1: Fig. S1c, d). The conversion of PI $(3,4,5)$ $\mathrm{P}_{3}$ from $\mathrm{PI}(4,5) \mathrm{P}_{2}$ by $\mathrm{PI} 3 \mathrm{~K}$ is instrumental for insulin signaling since $\mathrm{PI}(3,4,5) \mathrm{P}_{3}$ triggers phosphorylation of AKT [47-49]. Accordingly, ELISA assays (Fig. 1l, m) revealed a reduction in the activity of the synaptic isoform PI3Ky [50] following induction of IR, to a degree comparable to the treatment with the $\mathrm{PI} 3 \mathrm{~K} \gamma$ inhibitor AS-605240 (Fig. $1 \mathrm{~m}$ ). Immunoblotting of the eluted PI3K $\gamma$ revealed that the observed differences are not due to the amount of immunoprecipitated PI3K $\gamma$, but indeed relies on the activity of the enzyme (Additional file 1: Fig. S1e, f).

\section{IRS1 and InsR degradation requires neddylation}

IRS1 degradation could be a nodal point for the induction of synaptic IR. To address whether IRS1 degradation is proteasome-dependent, the proteasome inhibitor MG-132 was co-applied with TNF $\alpha$ and insulin to primary cortical culture (Fig. 2a). Expectedly, IRS1, IRS2 and InsR degradation was counteracted by pharmacological blockade of proteasomal degradation (Fig. 2b-d, Additional file 1: Fig. S2a, b). No regulation of the unrelated
Insulin Receptor Substrate p53 (IRSp53) was observed, which served as a negative control in this experiment (Additional file 1: Fig. S2a, c).

Cullins are components of a group of E3-ubiquitin ligases that have been implicated in the degradation of IRS1 [51, 52]. Neddylation, the attachment of the small ubiquitin-like protein NEDD8, is a posttranslational modification of Cullins that is necessary for their activation [53]. Once neddylated, Cullins promote ubiquitination of target proteins for proteasomal degradation. Consequently, we hypothesized that IRS1 might be degraded in a NEDD8-dependent manner. To test this hypothesis, we took advantage of the selective NEDD8activating enzyme (NAE) inhibitor MLN-4924 [54]. NAE is an E1-like enzyme that catalyzes the first reaction of the neddylation cascade. Similar to MG-132 treatment, bath application of MLN-4924 to primary cortical neurons together with TNF $\alpha$ and insulin for $24 \mathrm{~h}$ prevented IRS1, IRS2 and InsR degradation (Fig. 2e-h, Additional file 1: Fig. S2d, e), while it had no effect on levels of IRSp53 (Additional file 1: Fig. S2d, f). We next investigated whether MLN-4924 might also restore the responsiveness to insulin and found that inhibition of neddylation indeed rescued phosphorylation of InsR and AKT (Fig. 2i-l) as well as postsynaptic AKT activation (Fig. $2 \mathrm{~m}, \mathrm{n}$ ) in response to 15 -min insulin stimulation without affecting the total AKT levels (Additional file 1: Fig. S2g, h).

\section{Neddylation-dependent IRS1 degradation involves Cullin-7} Seven different Cullins are expressed in the brain and it has been suggested that among the various isoforms, Cullin-7 (CUL7) could have a specific role in the degradation of IRS1 at least in non-neuronal cells [51]. To test the

\footnotetext{
(See figure on next page.)

Fig. 1 Induction of neuronal insulin resistance (IR) in 21DIV primary neuronal cultures. a The schematic illustrates the protocol to induce IR in primary cortical and hippocampal neurons. Representative immunoblots (b) probed with antibodies detecting pAKT/pan-AKT, plnsR/pan-InsR, pIRS1/pan-IRS1; and quantitation of plnsR/pan-InsR ratio (c), pAKT S473/AKT ratio (d) and pIRS1 S612/IRS1 ratio (e) as well as total IRS1 (f) and InsR (g) protein levels in cortical primary neurons upon indicated treatments are shown. $\beta$-Actin was used as internal standard for protein loading. $\mathbf{c}$ Induction of IR results in a significantly reduced InsR phosphorylation in response to 15-min stimulation with insulin. $\mathbf{d}$ Scatter dot-bar plots showing significant reduction in pAKT level responsiveness of neurons to 15 -min stimulation with insulin upon induction of IR ( $n=10$ ). Treatment of cortical neurons with insulin/TNFa for $24 \mathrm{~h}$ resulted in enhanced levels of pIRS1 S612 (e, $n=11$ for groups 1 and $2 ; n=7$ for groups 3 and 4 ) and reduced levels of total IRS1 (f,$n=11$ for groups 1 and 2; $n=9$ for groups 3 and 4 ). $\mathbf{h}, \mathbf{i}$ Immunoblot analysis of synaptosomes (Syn) and the respective crude membrane fraction (P2) after induction of IR ( $n=5)$. i Induction of IR significantly reduced responsiveness to insulin as measured by PAKT/AKT ratio in synaptosomal fraction. $\mathbf{j}$ IR reduced levels of pAKT at synapses labelled with Shank3. Confocal images depict dendrites of hippocampal neurons immunostained with antibodies directed against pAKT \$473 and Shank3. Original pixel intensities from 0 to 255 are presented as a gradient lookup table. Scale bar, $10 \mu \mathrm{m}$. k Scatter dot plot depicting synaptic pAKT immunofluorescence intensity quantified within a Shank3 mask normalized to control. $n=45$ for groups 1 and $4 ; n=46$ for group $2 ; n=43$ for group $3 ; n$ numbers refer to the number of dendrite segments from different neurons acquired from at least three independent coverslips. I Schematic representation of PI3Ky activity assay where orange circles represent $\mathrm{PI}(3,4) \mathrm{P}_{2}$ and green circles represent $\mathrm{PI}(3,4) \mathrm{P}_{3}$. $\mathbf{m}$ Quantification of the substrate $\mathrm{PI}(4,5) \mathrm{P}_{2}$ through colorimetric reaction in $\mathrm{PI}(3,4,5) \mathrm{P}_{3}$-coated detection plate for competitive binding. Cell extracts treated with the PI3Ky selective inhibitor AS-605240 during the enzymatic reaction were used as a negative control. $n=8$ for groups 1 and $2 ; n=6$ for group 3 . ${ }^{* * *} P<0.001,{ }^{* *} P<0.01,{ }^{*} P<0.05$ versus control, by two-way ANOVA followed by Bonferroni's post-hoc test. Two-tailed Student's t-test was used in $\mathbf{m}$. n.s. =non-significant. Data are presented as the mean \pm SEM
} 


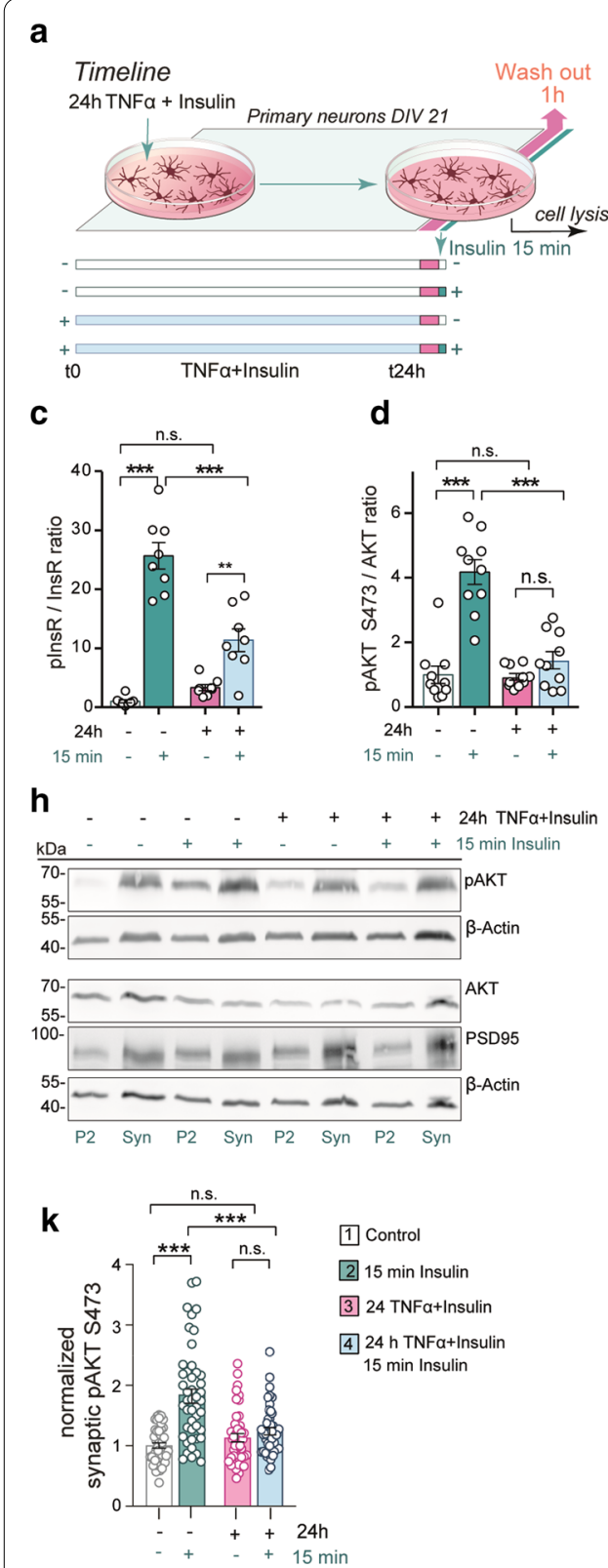

b
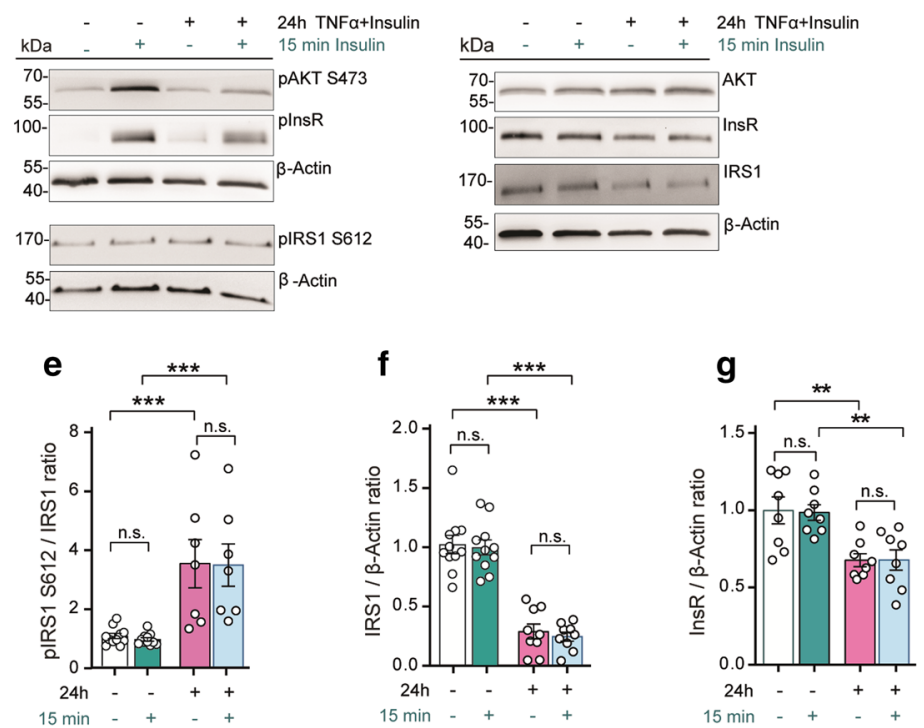

i
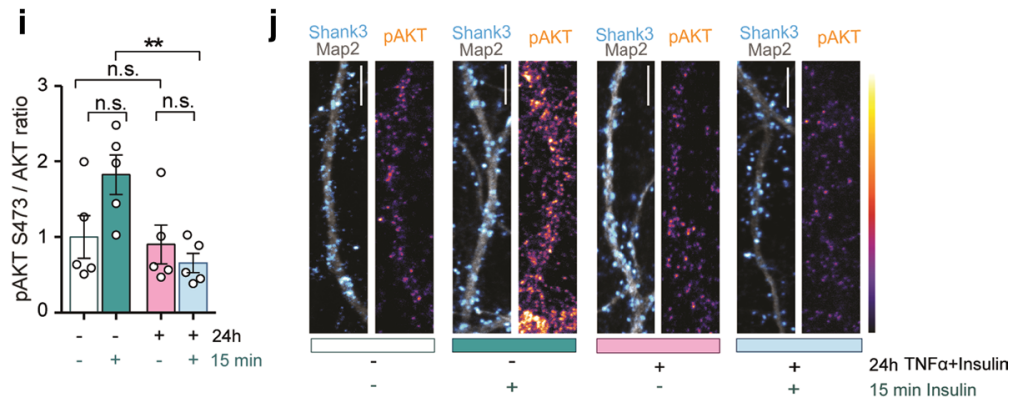

I
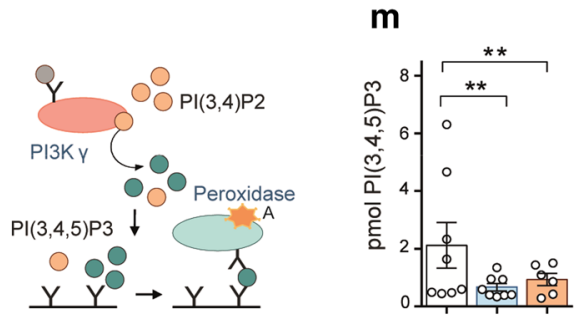

1 Control

2 24h TNFa+Insulin

3 AS-605240

Fig. 1 (See legend on previous page.)

hypothesis that CUL7 is a major regulator of neuronal IRS1 ubiquitination, we co-expressed several Myc-tagged Cullins along with a GFP-P2A-CDB-His-IRS1 fusion protein and HA-ubiquitin in HEK293T cells. Subsequently, we pulled down CDB-His-IRS1 with a chitin resin to purify IRS1 and to detect the level of its ubiquitination with anti-HA antibodies (Fig. 3a, b). Strikingly, the level of IRS1 ubiquitination was significantly higher only in the case of co-expression with CUL7 but not of other Cullins (Fig. 3a, b). Concomitantly, the total level of CDB-HisIRS1, as revealed by the ratio of IRS1 and GFP that were expressed from the same plasmid, was significantly lower in the inputs in the presence of CUL7, suggesting IRS1 degradation (Fig. 3c). This indicates that CUL7 might indeed play a major role in the degradation of IRS1.

We next investigated whether IRS1 ubiquitination triggered by CUL7 is regulated by neddylation. To this end, we co-expressed GFP-P2A-CBD-His-IRS1 together with Myc-CUL7 in HEK293T cells, treated them with either MLN-4924 or MG-132 as a positive control and assessed the level of IRS1 ubiquitination following protein pulldown using anti-ubiquitin antibody for detection of 


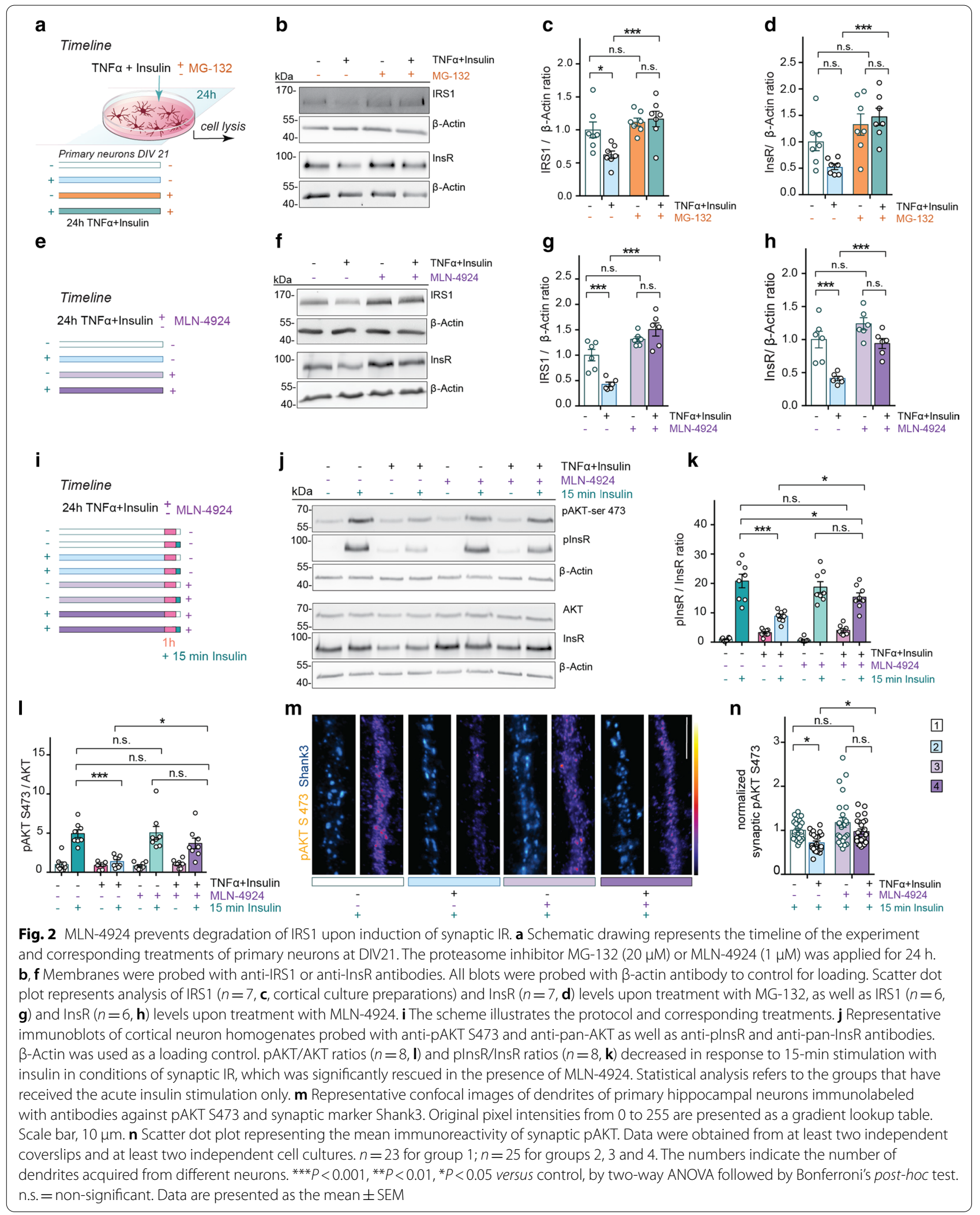


endogenous ubiquitin (Fig. 3d-f). Interestingly, inhibition of neddylation reduced IRS1 ubiquitination, indicating neddylation and subsequent activation of CUL7 (Fig. 3e, f). We therefore next infected primary cortical neurons with AAV9 expressing HA-NEDD8 and subsequently performed immunoprecipitation experiments using anti-HA microbeads (Fig. 3g). Interestingly, CUL7 co-immunoprecipitated with NEDD8 in HA-NEDD8 infected neurons (Fig. 3h) and co-immunoprecipitation of CUL7 was significantly enhanced when neurons were treated with TNF $\alpha$ and insulin for $24 \mathrm{~h}$ (Fig. 3h, i). In accordance with the role of CUL7 in driving synaptic IR and IRS1 degradation, shRNA knockdown of CUL7 in primary neurons restored synaptic responsiveness to insulin stimulation in conditions of synaptic IR by increasing synaptic pAKT levels (Fig. 3j, k, Additional file 1: Fig. S3a, b).

\section{Induction of synaptic IR by insulin and TNFa is related to $A \beta$ pathology}

We next investigated the individual contribution of elevated insulin or TNF $\alpha$ levels to synaptic IR (Additional file 1: Fig. S3c, d). Quantitative immunocytochemistry revealed that bath application of TNF $\alpha$ or insulin individually already reduced AKT activation, while co-application of both resulted in a further reduction of AKT phosphorylation (Additional file 1: Fig. S3c, d). Interestingly, co-application of $A \beta 3(\mathrm{pE})-42$ and insulin to mixed neuronal cultures containing astroglia resulted in synaptic IR to a similar extent as the combined treatment with TNF $\alpha$ and insulin (Additional file 1: Fig. S3e, f). Moreover, the effects of $A \beta 3(\mathrm{pE})-42$ on pAKT and pIRS1 levels were blocked by bath application of a monclonal neutralizing anti-TNF $\alpha$ antibody (Additional file 1: Fig. S3g-j), indicating that the effects of $A \beta 3(\mathrm{pE})-42$ on synaptic IR are indeed largely mediated by the proinflammatory cytokine TNF $\alpha$.
Induction of MetS in TBA2.1 mice can serve as an in vivo model for synaptic IR and amyloidosis in high-risk aging We therefore next wondered whether neuroinflammation and $A \beta$ pathology in $A D$ interact with MetS to induce synaptic IR in vivo. TBA2.1 mice express $A \beta 3(\mathrm{pE})-42$ under a Thy-1 promoter and homozygous animals show profound AD pathology [27] and very prominent neuroinflammation resembling in this respect human pathology [20]. However, heterozygous mice within the first 6 months of life exhibit no such phenotype, which is probably due to a lower amyloid load [27]. Hence, they might be well suited as a model of $A \beta$-induced neuroinflammation that is sub-threshold for AD but that might be exacerbated in MetS and accompanied by synaptic IR if mice are fed with a western HFD. Therefore, we were feeding male heterozygous TBA2.1 mice and corresponding WT control mice until they reached a 70\% gain in body weight (Additional file 1: Fig. S4a). This regimen resulted in clear indications of MetS in mice of both genotypes fed with a HFD as evidenced by a blunted glucose response to insulin as well as elevated serum glucose, insulin and cholesterol levels (Additional file 1: Fig. S4b-e).

\section{HFD causes glial activation and induces neuronal cell loss in the CA1 region of hippocampus in TBA2.1 mice}

Glial activation is a vital part of the neuroinflammatory response in $\mathrm{AD}[20,21]$ and neuronal cell loss in the hippocampal CA1 region is a hallmark of the early stage of AD [55]. We found a significantly increased number of Iba1-positive microglia and increased GFAP immunoreactivity in heterozygous TBA2.1 mice fed with a HFD as compared to controls (Additional file 1: Fig. S4f-h). In addition, we observed a significant reduction of NeuNpositive neurons in the pyramidal layer of the hippocampal CA1 region (Additional file 1: Fig. S4f, i). Moreover, the levels of TNF $\alpha$ were elevated in TBA2.1 mice irrespective of the diet (Additional file 1: Fig. S4j).

\footnotetext{
(See figure on next page.)

Fig. 3 IRS1 ubiquitination and degradation depend on neddylation of CUL7. a IRS1 ubiquitination is enhanced in the presence of CUL7. HEK293T cells were co-transfected with GFP-P2A-CBD-His-IRS1, HA-Ubiquitin vectors together with one of the cullin's family members or empty Myc-vector for control. CBD-His-IRS1 was pulled down with chitin resin for IRS1 enrichment. Quantitation of the levels of pulled-down ubiquitinated IRS1 (bb, $n=4$ independent experiments) and of total cell homogenates probed with anti-His antibody, and IRS1 expression was normalized to GFP in c $(n=4) ;{ }^{* * *} P<0.0001,{ }^{*} P<0.05$ versus control, by two-way ANOVA followed by Bonferroni's multiple comparison test. $\mathbf{d}$ Schematic representation of the expression plasmid and the treatment. e Representative immunoblots probed with anti-Ubiquitin, anti-IRS1, anti-Myc, and anti-GFP antibodies. f Depicted is a scattered dot plot showing reduced IRS1 ubiquitination in the presence of MLN-4924 $(n=6)$. $\mathbf{g}$ Schematic of the protocol used to induce IR in DIV11 primary cortical neurons, infected with either AAV9-HA-NEDD8 or AAV9-HA-tag. $\mathbf{h}$, i Synaptic insulin resistance enhanced the association of NEDD8 with CUL7 as revealed with co-immunoprecipitation experiments from primary neurons infected with HA-NEDD8. $\mathbf{i}$ Scattered dot plots show quantification of CUL7 in co-IPs normalized to the input $(n=4)$. $\mathbf{j}$ Representative confocal images of dendrites of primary hippocampal neurons infected with AAV9-shRNA CUL7 and AAV9-scr shRNA and immunolabeled with antibodies against pAKT S473 and the synaptic marker Shank3. Original pixel intensities from 0 to 255 are presented as a gradient lookup table. Scale bar, $5 \mu \mathrm{m}$. $\mathbf{k} n=2566$ for group 1; $n=1171$ for group $2 ; n=1319$ for group $3 ; n=1194$ for group $4 ; n=857$ for group $5 ; n=1059$ for group 6 . Violin plot representing means of the pAKT at synaptic sites. Numbers refer to the number of spines detected by the Shank 3 mask. ${ }^{* *} P<0.001,{ }^{* *} P<0.01,{ }^{*} P<0.05$ versus control, by two-way ANOVA followed by Bonferroni's post-hoc test. A two-tailed Student's t-test was used in (f). n.s. =non-significant. Data are presented as the mean \pm SEM
} 


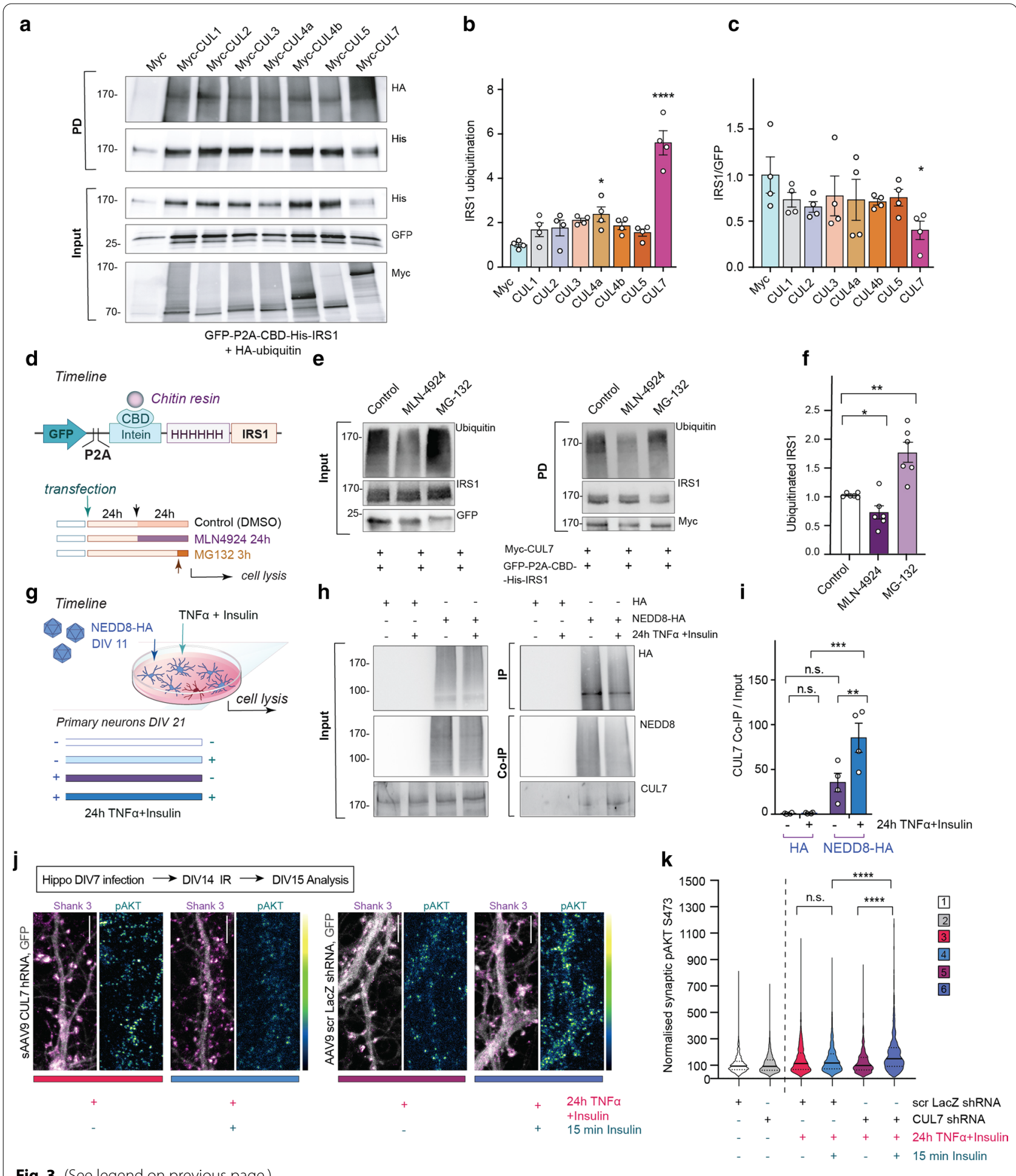

Fig. 3 (See legend on previous page.) 


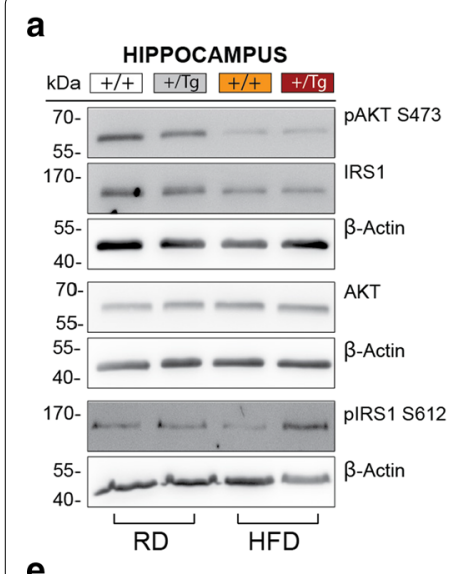

e
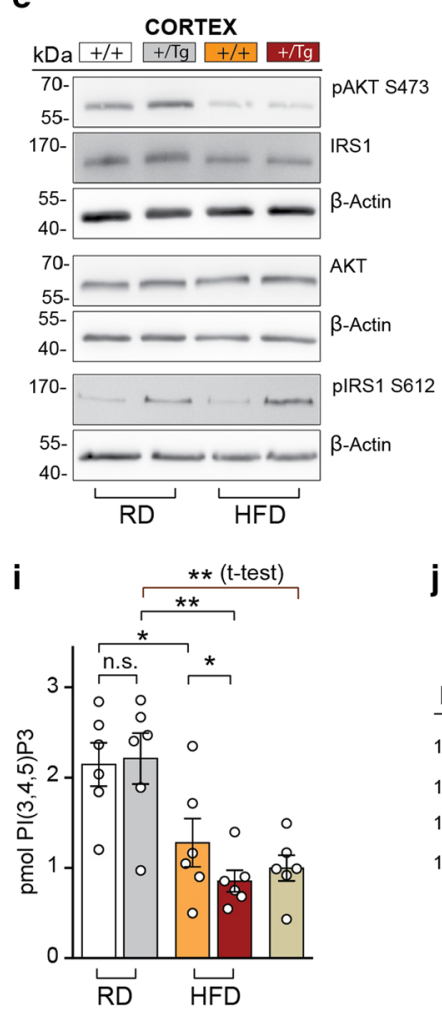

b

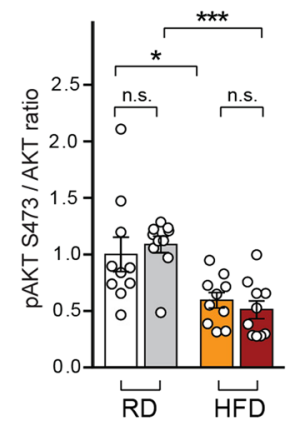

f

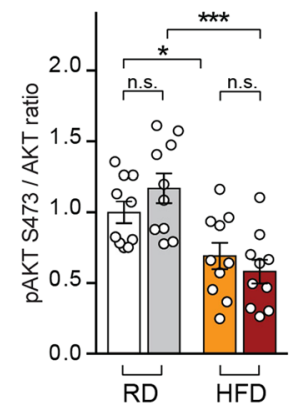

C

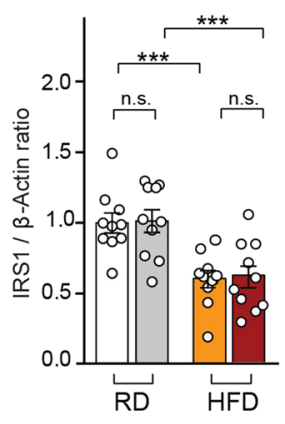

g

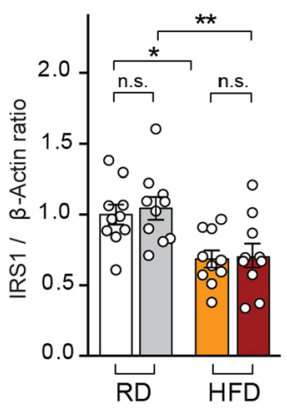

d

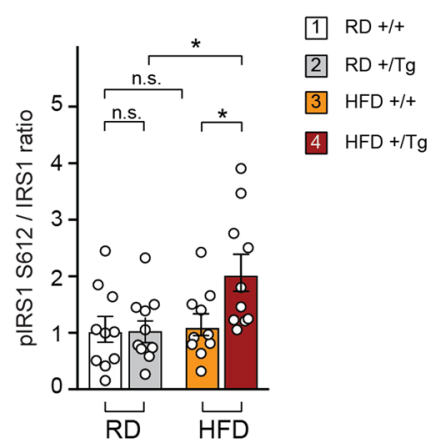

h

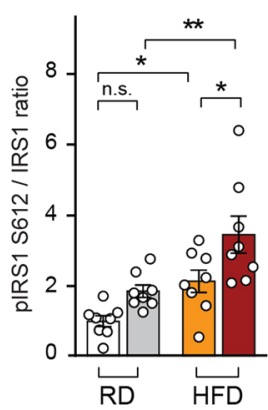

j

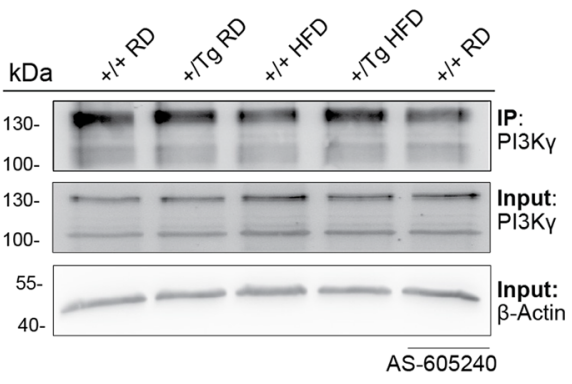

k

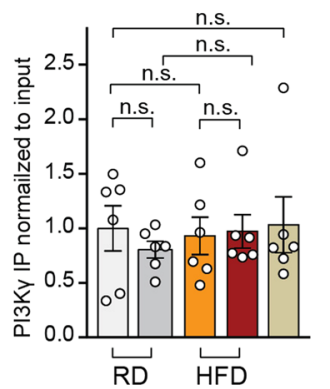

$1 \mathrm{RD}+/+$

2. $\mathrm{RD}+/ \mathrm{Tg}$

$3 \mathrm{HFD}+/+$

$4 \mathrm{HFD}+/ \mathrm{Tg}$

$5 \mathrm{RD}+/+$

+AS605240

Fig. 4 HFD promotes synaptic IR in wild-type and heterozygous TBA2.1 mice. Representative immunoblots of total protein extracts from hippocampus (a) and cortex (e) of wild-type (+/+) or heterozygous TBA2.1 (Tg) mice fed with a RD or HFD. Membranes were probed with antibodies detecting PAKT (Ser473), AKT, pIRS1 (Ser612) and IRS1 as well as $\beta$-actin as a loading control. Scatter dot plots of the normalized pAKT (b, $\mathbf{f})$, IRS1 $(\mathbf{c}, \mathbf{g})$ and pIRS $(\mathbf{d}, \mathbf{h})$ in hippocampus $(n=10)$ and cortex $(n=10)$. i Endogenous PI3KY was immunoprecipitated from hippocampal lysates of wild-type and heterozygous TBA2.1 mice fed with a RD or HFD. The amount of PI $(3,4,5) \mathrm{P}_{3}$ produced by the enzyme coupled to the beads was determined by ELISA. The inhibitor AS-605240 was added to the wild-type/RD control group and used as a negative control $(n=6)$. $\mathbf{j}, \mathbf{k} \mid \mathrm{mm} u n o b l o t$ analysis showing no differences in the amounts of immunoprecipitated PI3KY between wild-type or heterozygous TBA2.1 mice fed with a RD or HFD $(n=6) .{ }^{* * *} P<0.001,{ }^{* *} P<0.01,{ }^{*} P<0.05$ versus control by two-way ANOVA followed by Bonferroni's post-hoc test. n.s. = non-significant. Two-tailed Student's $t$-test was done to compare +/+RD versus +/+RD treated with AS-605240 in $\mathbf{i}$ and $\mathbf{k}$. Data are presented as the mean \pm SEM

\section{HFD induces synaptic IR in mice}

We asked next whether the combination of high amyloid load and HFD can induce synaptic IR. Hippocampi and cortices from WT and heterozygous TBA2.1 mice kept on RD or HFD were dissected and levels of pAKT and pIRS1 as well as the total protein levels of IRS1 were examined (Fig. 4a-h). We observed a substantial reduction of the basal AKT phosphorylation in the hippocampus (Fig. 4a, b) and cortex (Fig. 4e, f) of TBA2.1 mice fed with a HFD. This was accompanied by reduced IRS1 and 


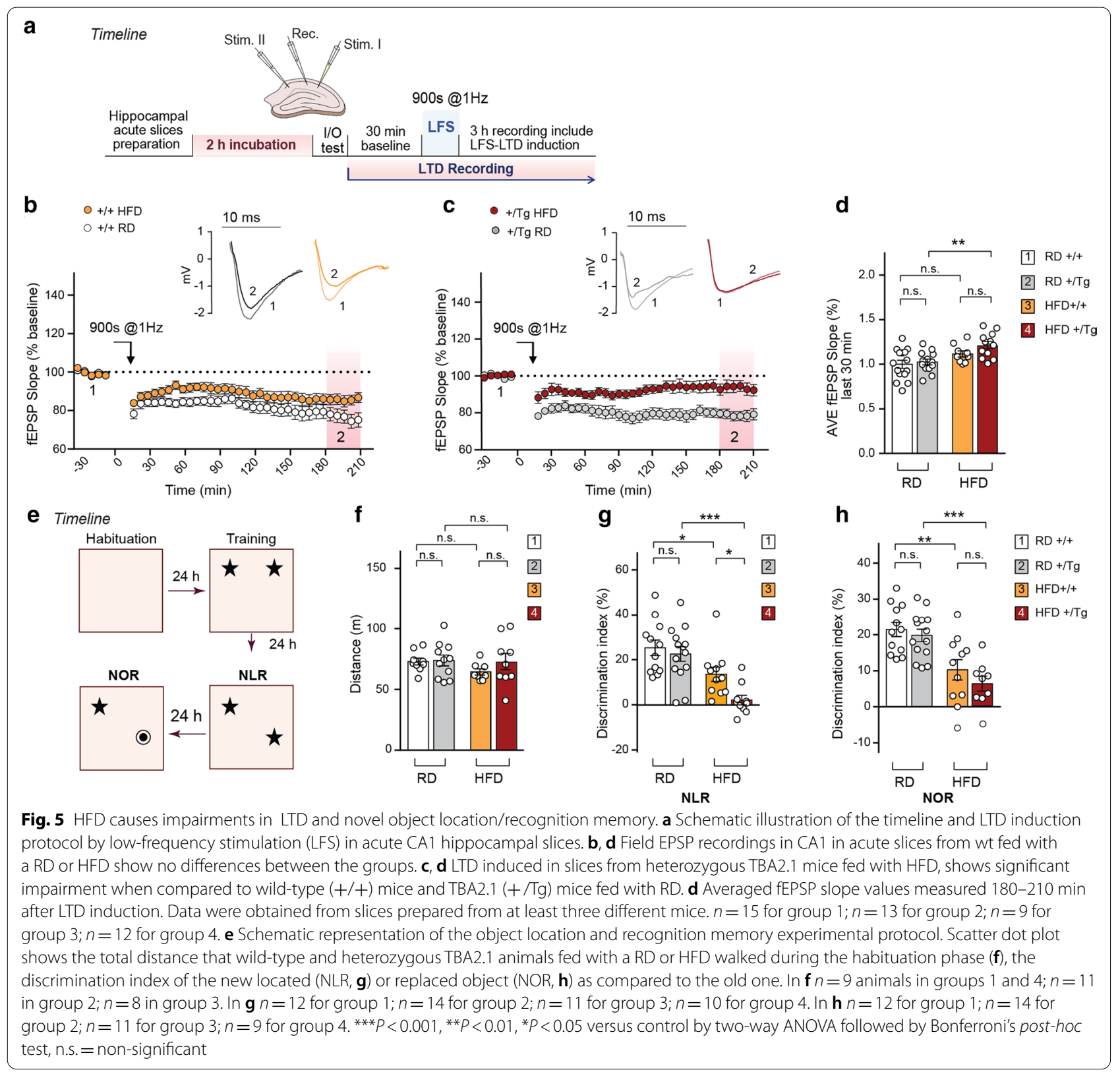

IRS2 protein levels (Fig. 4a, c, e, g, Additional file 1: Fig S4k-n) and increased phosphorylation of IRS1 at the inhibitory serine residue only in TBA2.1 mice fed with a HFD (Fig. 4a, d, e, h).

In order to address the effects of HFD on synaptic IR, synaptosomes were prepared and insulin responsiveness was tested ex vivo upon stimulation with $100 \mathrm{nM}$ insulin for $15 \mathrm{~min}$ in the presence of ATP. As expected, we observed efficient InsR phosphorylation in response to insulin, which was significantly reduced in synaptosomes of mice fed with a HFD (Additional file 1: Fig. S4o-r).
We next performed endogenous immunoprecipitation of PI3K $\gamma$ from the total homogenate of heterozygous TBA2.1 mouse hippocampi and $\mathrm{PI}(3,4,5) \mathrm{P}_{3}$ produced by the enzyme was measured by competitive colorimetric ELISA. The reduced amount of $\mathrm{PI}(3,4,5) \mathrm{P}_{3}$ converted from the substrate $\mathrm{PI}(4,5) \mathrm{P}_{2}$ correlates to the reduced enzymatic activity of PI3K $\gamma$ in animals who received a HFD (Fig. 4i-k). Interestingly, PI3K $\gamma$ activity was even further reduced in TBA2.1 mice fed with a HFD (Fig. $4 \mathrm{i}-\mathrm{k})$. 
TBA2.1 mice fed with HFD display impairments in synaptic plasticity and novel object location/recognition memory Insulin signaling and $\mathrm{PI} 3 \mathrm{~K} \gamma$ activation in the brain have been shown to be instrumental for the induction of $N$-Methyl- $D$-aspartate receptor (NMDAR)-dependent long-term depression (LTD) in the CA1 region of hippocampus $[50,56]$. Therefore, we chose this type of synaptic plasticity to determine the cellular consequences of synaptic IR. To this end, NMDAR-dependent LTD was induced with low-frequency stimulation at Schaffercollaterals in the CA1 region of acute hippocampal slices (Fig. 5a, Additional file 1: Fig. S5a, b). We found that the fEPSP slope returned to the baseline level following LTD induction only in slices obtained from heterozygous TBA2.1 mice under a HFD regime (Fig. 5b-d).

Learning and memory formation for the spatial localization and recognition of objects requires synaptic plasticity of CA1 neurons and the induction of NMDAR-dependent LTD [57, 58]. When we next tested for such memory tasks in an open field (Fig. 5e), we observed no difference in locomotor activity despite the striking differences in body weight among the groups (Fig. 5f). However, animals subjected to a HFD exhibited a lower discrimination of the newly located (Fig. 5g) and novel object (Fig. 5h) when compared to WT mice fed with a RD. Notably, the discrimination of the newly located object was significantly worse in TBA2.1 mice on HFD as compared to the corresponding control groups (Fig. $5 \mathrm{~g}$ ), which correlates with the impairment in LTD (Fig. 5c, d).

MLN-4924 injection in TBA2.1 mice ameliorates synaptic IR and prevents HFD-induced synaptic plasticity and memory impairment

In the final set of experiments, we investigated whether the expression of synaptic IR in mice fed with a HFD might be a consequence of neddylation-dependent degradation of IRS1. To study this question, we administered MLN-4924 and analyzed whether this treatment counteracts neuronal IRS1 degradation and protects from cognitive and synaptic plasticity decline. No significant weight loss was observed following MLN-4924 injection (Additional file 1: Fig. S6a) and no indication for alleviating peripheral parameters of MetS was found (Additional file 1: Fig. S6b-e). However, the pIRS1/IRS1 ratio in animals injected with MLN-4924 was reduced, suggesting that the treatment might rescue synaptic IR (Fig. 6a, b). To investigate the effects of MLN-4924 on synaptic function, NMDAR-dependent LTD was induced in the hippocampal CA1 region with low-frequency stimulation of Schaffer-collaterals in acute slices obtained from heterozygous TBA2.1 mice fed with a HFD. In these experiments, we observed a rescue of LTD in obese TBA2.1 mice injected with MLN-4924 as compared to those injected with vehicle (Fig. 6c-e, Additional file 1: Fig. S6f, g). Interestingly, this effect was absent in TBA2.1 mice fed with a regular diet (Additional file 1: Fig. S6h-1). Most importantly, inhibition of neddylation with MLN-4924 improved hippocampal CA1 LTD-dependent learning and memory as evidenced by an enhanced discrimination index in the novel location (Fig. 6f) but not in the novel object recognition task (Fig. 6g). Administration of MLN-4924 did not affect the locomotor activity (Additional file 1: Fig. S6m).

\section{Discussion}

Several studies have shown that synaptic IR in conjunction with chronic inflammation and a high amyloid load is part of a pathological triad that puts individuals at a high risk of developing LOAD with increasing age [10, 17-19]. Impaired neuronal insulin signaling by itself negatively affects cognition and while the underlying mechanisms of synaptic IR are less clear, a number of mechanisms have been proposed for the interaction between neuroinflammation and $\mathrm{A} \beta$-induced synaptic dysfunction $[17,20,36]$.

In this study, we report that MetS, neuroinflammation and a high amyloid load essentially converge on neddylation of Cullins and subsequent ubiquitination of the IRS1 scaffold in the hippocampus to induce synaptic IR (Fig. 7), and impairment in LTD and learning of novel object location. Although not directly addressed in this study, we consider it likely that this mechanism might also impact the progression of LOAD. In addition, we found that inhibition of neddylation might be a useful molecular entry point to interrupt this pathological triad. Collectively, the results raise a number of interesting points that we want to discuss in more detail.

\section{Neddylation and synaptic function}

Relatively few studies have addressed the role of neddylation in synaptic function and neddylation in neurons as such has not been studied in much detail yet. Previous work has shown that the synaptic scaffolding protein postsynaptic density-95 (PSD95) is a substrate for neddylation [59] and that neddylation of PSD95 is important for spine stability [59]. In the same study, it was also shown that forebrain-specific knockout of NEDD8-activating enzyme (NAE1) results in several impairments in spine maturation, stability and function [59]. It is therefore no surprise that inhibition of neddylation results in deficits of hippocampal synaptic plasticity [60]. In addition, it was found that synaptic activity regulates neddylation of Cullins in the nucleus and, here in particular Cullin-4B (CUL-4B), which is instructive 


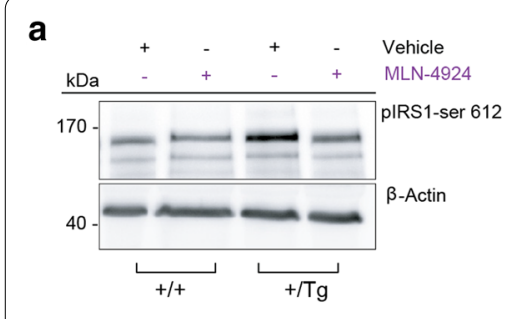

C
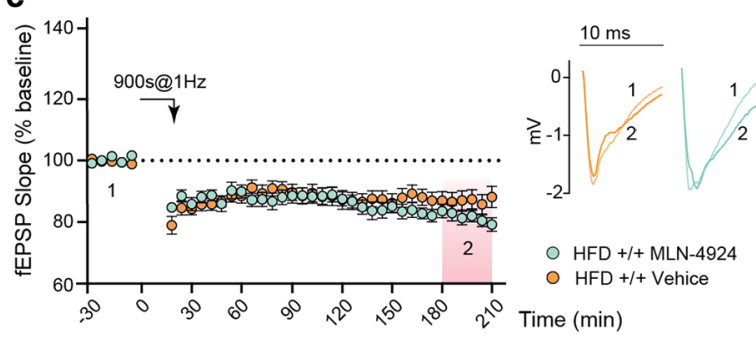
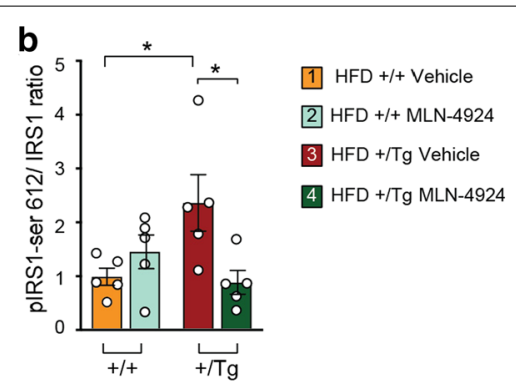

1. $\mathrm{HFD}+/+$ Vehicle

$3 \mathrm{HFD}+/ \mathrm{Tg}$ Vehicle

4 HFD +/Tg MLN-4924

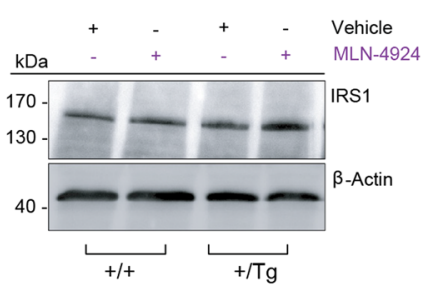

d

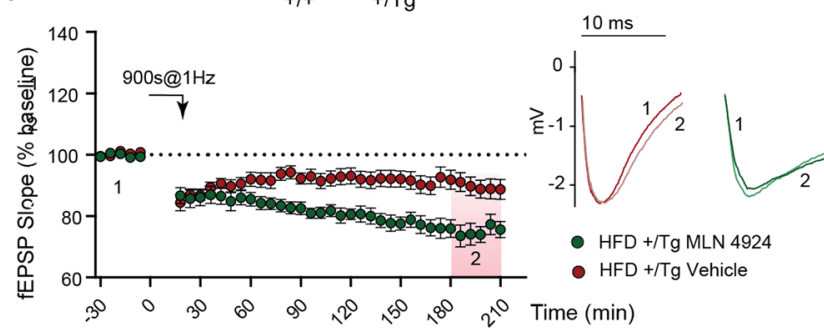

e

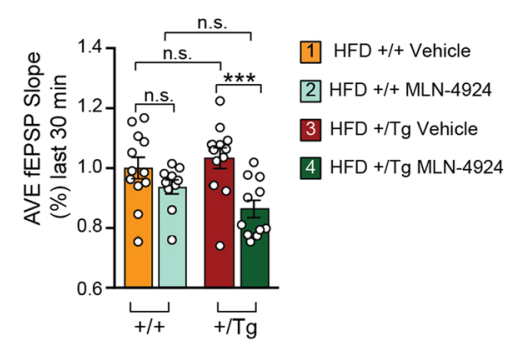

f

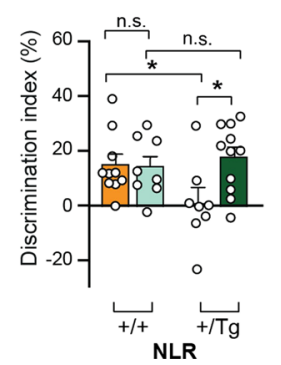

9

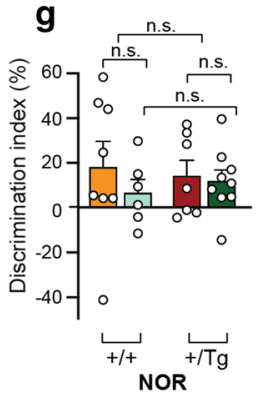

(1) HFD +/+ Vehicle

2 HFD +/+ MLN-4924

3 HFD $+/ T g$ Vehicle

4 HFD +/Tg MLN-4924

Fig. 6 The treatment with MLN-4924 of mice fed with the HFD ameliorates synaptic IR and memory impairment. $\mathbf{a}$, $\mathbf{b}$ Representative immunoblots and quantification of total hippocampal extracts showing a reduction in pIRS1/IRS1 ratio upon the MLN-4924 treatment of wild-type or heterozygous TBA2.1 fed with HFD. IRS1 protein level was normalized to $\beta$-actin. $n=5$. $P<0.05$ versus control, by two-way ANOVA followed by Tukey's post-hoc test. c, d Quantification of fEPSP slope values in wild-type and heterozygous TBA2.1 mice fed with HFD and injected with MLN-4924 or vehicle shows the rescue of LTD upon the treatment with MLN-4924. e Averaged fEPSP slope values measured $180-210$ min after LTD induction. $n=12$ for groups 1 and $3 ; n=10$ for group $2 ; n=11$ for group $4 . \mathbf{f}, \mathbf{g}$ Behavioral assessment in mice injected with MLN-4924 or vehicle. $\mathbf{f}$ Scatter dot plot shows a rescue of the discrimination index of the new located (NLR) without alterations in replaced object location (NOR, $\mathbf{g}$ ). In $\mathbf{f}$ $n=10$ for group; $n=8$ for groups 2 and $3 ; n=11$ in group 4 . $\ln \mathbf{g} n=8$ for group $1 ; n=6$ for group $2 ; n=7$ for group $3 ; n=9$ for group 4 . $n$ indicates the number of animals. ${ }^{* *} P<0.001,{ }^{*} P<0.05$ versus control, by two-way ANOVA followed by Bonferroni's post-hoc test. n.s. $=$ non-significant. Data are presented as the mean \pm SEM

for the subsequent degradation of the de novo DNAmethytransferase DNMT3A1 [61]. While some reports indicate a synaptic function of Cullins in Drosophila [6, 62], the literature on Cullins in mammalian synapses is sparse. We show here that CUL7 seems to play an important role in the induction of synaptic IR (Fig. 7). This is in line with a previous report that showed the involvement of CUL7 in IRS1 ubiquitination in non-neuronal cells $[51,52]$. Several studies have proposed mechanisms for the interplay of IR and amyloidosis in AD and its relevance for disease progression [19] and our finding might contribute a novel approach to restoring cerebral insulin function that could offer therapeutic benefits given that neddylation proved to be a druggable target [63]. In addition, our results suggest that peripheral administration of the NAE-1 inhibitor MLN-4924 is in principle feasible to target synaptic processes.

\section{A novel molecular entry point to treat synaptic IR?}

Unfortunately, still very little is known about which synaptic proteins are neddylated and how neddylation affects protein function. An intriguing question is therefore whether and if yes, how neddylation might be regulated at synaptic sites. In a previous study, we observed that activation of glutamate receptor subunit 2A-containing NMDAR at synaptic sites enhances neddylation of CUL4B in the nucleus via activation of CaMKIV [61]. Whether the NMDAR $\mathrm{Ca}^{2+}$-signal at synaptic sites can also enhance local neddylation of other substrates is currently unknown. In fact, it is even unclear whether the 

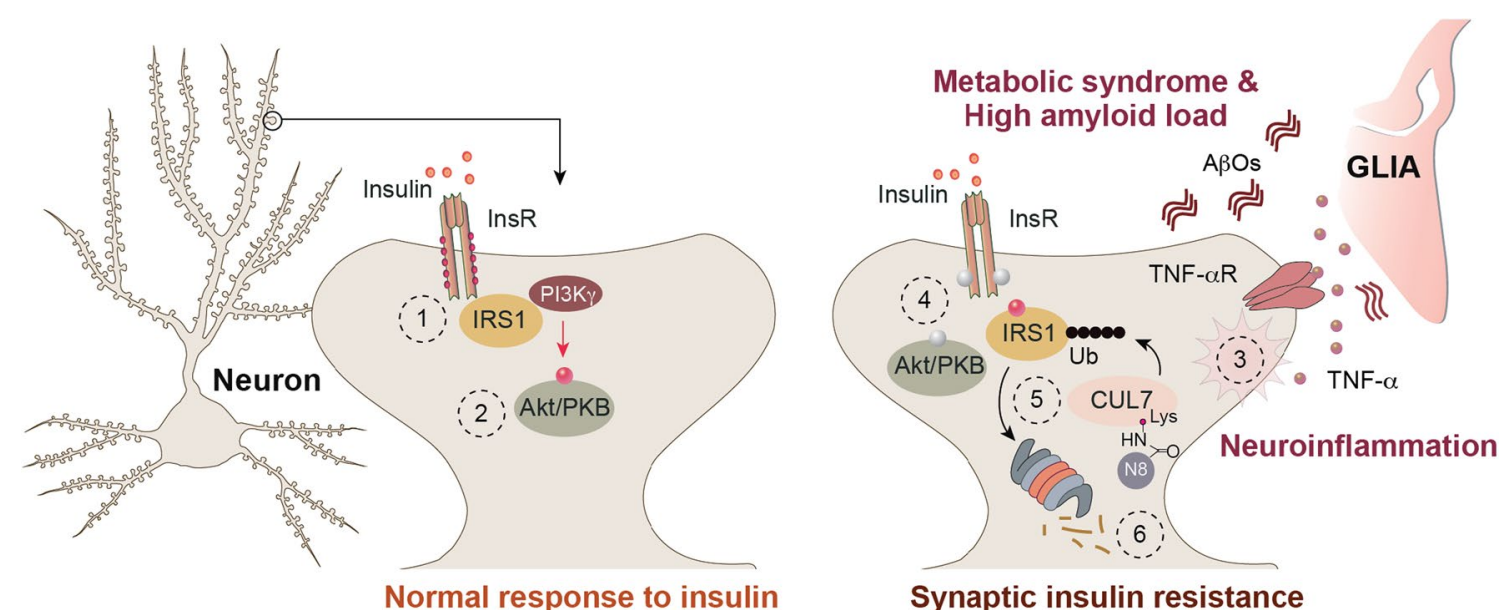

Fig. 7 Neddylation-dependent IRS1 degradation is a nodal point in synaptic insulin resistance. Exposure to insulin results in phosphorylation of insulin receptors (InsR) (1) with subsequent activation of ATK/PKB (2). Both high amyloid load via stimulation of TNFa release from glia (3) and MetS alter neuronal responsiveness to insulin (induce synaptic insulin resistance) as evidenced by reduced phosphorylation of InsR and the downstream effector AKT (4) and enhanced phosphorylation of IRS1. In parallel, synergism between MetS, high amyloid load and neuroinflammation promotes neddylation of CUL7 (5) and subsequent degradation of IRS1 (6)

machinery for neddylation is at all present at synapses. NEDD8 has relatively low abundance at synaptic sites as compared to the nucleus [61]. Accordingly, it might be difficult to identify signaling pathways that regulate either directly or indirectly neddylation. In non-neuronal cells, neddylated proteins are prominently associated with the microtubule cytoskeleton [64] and it is likely that apart from Cullins, microtubules and their associated proteins might be a major part of the neuronal neddylome. Administration of the NEDD8-inhibitor MLN-4924 at much higher concentrations than those employed in the present study as well as NAE1 gene knockout results in synaptic loss and impaired synaptic plasticity $[59,65]$. It is therefore advisable to identify specific neddylated targets in future work to prevent negative effects of any intervention on synaptic structure and function. As outlined above, one of those could be CUL7. It is involved in IRS1 ubiquitination (Fig. 3a-f) [63] and shRNA knockdown rescued at least partially synaptic IR and we did not observe spine loss or reduced dendrite complexity following protein knockdown (data not shown).

\section{Cullin7: a nodal point in synaptic IR, neuroinflammation and $A \beta$-oligomer signaling?}

Several signaling pathways have been identified that might contribute to the intricate balance between IRS1 phosphorylation at serine or tyrosine residues, which in turn determines the extent and magnitude of insulin actions [42]. In AD, multiple factors are known to activate the JNK pathway, including $A \beta$ accumulation and TNF $\alpha$ signaling [20,66]. JNK activation results in IRS1 serine phosphorylation, blocking downstream insulin signaling, and increases the susceptibility of IRS1 to degradation $[67,68]$. Impaired insulin signaling in turn accounts for the subsequent activation of glycogen synthase kinase 3 beta and accumulation of $\mathrm{A} \beta$ and hyperphosphorylated Tau $[68,69]$. In this scenario, the most plausible initial trigger for convergence of pathological events is the facilitation of synaptic IR by TNF $\alpha$ activation of the JNK pathway with the ensued IRS1 inhibition and degradation, which then has a major negative impact on synaptic function, synaptic plasticity, and synaptic connectivity. What is currently missing is a molecular regulatory link between increased neddylation of Cullins and IRS1 degradation under such conditions. An intriguing hypothesis concerns the activation of NAE1 itself by the TNF $\alpha /$ JNK pathway or signaling components of the InsR. Another interesting candidate molecule in this respect is dsRNAdependent protein kinase (PKR). PKR is activated by $A \beta$ and elevated levels of phophorylated PKR are present in postmortem AD brains [70]. PKR activation occurs in a TNF $\alpha$-dependent manner and this, in turn, results in IRS1 inhibition, synaptic loss and memory impairment [71]. Most importantly, PKR-knockout mice are resistant to the detrimental effects of $A \beta$ and TNF $\alpha$ [72] and bolstering insulin signaling can counteract the PKR-related AD phenotypes [71]. Thus, PKR might be a key modulator of insulin sensitivity that could underlie memory impairment in MetS and obesity as well as AD and it is likely that a molecular link will exist with other signaling components of the pathological triad consisting of synaptic IR, neuroinflammation and oligomeric $A \beta$. 


\section{Conclusions}

In summary, the present work suggests that neddylation of proteins and in particular Cullins at synaptic sites plays an important role in synaptic IR (Fig. 7). Pharmacological inhibition of neddylation rescues memory impairment and synaptic plasticity in an animal model of high-risk aging and the study paves the way for a systematic investigation of further molecular targets and a deeper appreciation of the interplay between key determinants of lifestyle and age-related pathology.

\begin{abstract}
Abbreviations
AAV9: Adeno-associated virus-9; aCSF: Artificial cerebrospinal fluid; AD: Alzheimer's disease; AB: Amyloid- $\beta$; Co-IP: Co-immunoprecipitation; DIV: Day(s) in vitro; ELISA: Enzyme-linked immunosorbent assay; fEPSPs: Field excitatory postsynaptic potentials; GFAP: Glial fibrillary acidic protein; HA-tag: Human influensa hemagglutinin; HFD: High-fat diet; InsR: Insulin receptor; IRS: Insulin receptor substrate; IR: Insulin resistance; JNK: C-Jun-N- terminal kinase; LOAD: Late-onset Alzheimer's disease; LTD: Long-term depression; MetS: Metabolic syndrome; NMDAR: N-Methyl-D-aspartate receptor; NAE1: NEDD8-activating enzyme; NEDD8: Neural precursor cell-expressed developmentally downregulated gene 8; NeuN: Neuronal nuclear antigen and neuron differentiation marker; $\mathrm{PI}(3,4) \mathrm{P}_{2}$ : Phosphatidylinositol (3,4)-biphosphate; $\mathrm{PI}(3,4,5) \mathrm{P}_{3}$ : Phosphatidylinositol $(3,4,5)$-triphosphate; PKR: Protein kinase R; PSD95: Postsynaptic dendisty-95; TNFa: Tumor necrosis factor a.
\end{abstract}

\section{Supplementary Information}

The online version contains supplementary material available at https://doi. org/10.1186/s40035-021-00277-8.

Additional file 1. Fig. S1. Induction of synaptic IR in primary neurons. Fig. S2. Proteasomal degradation of IRS2 is not affected by neddylation. Fig. S3. CUL7 KD does not alter insulin signaling and $A \beta 3(\mathrm{pE})$ application exacerbates IR. Fig. S4. MetS induces neuronal cell loss, astroglial and microglial activation in the hippocampal CA1 region of heterozygous TBA2.1 mice. Fig. S5. Baseline recordings of fEPSP in hippocampal acute slices from WT and heterozygous TBA2.1 mice fed with a RD or HFD. Fig. S6. Characterization of the effects of MLN-4924 on basic metabolic parameters, basal fEPSP slope and LTD-dependent learning and memory in WT and heterozygous TBA2.1 mice fed with a RD or HFD. Table S1. Expression constructs and antibodies used in this study.

\section{Acknowledgements}

We are grateful to Corinna Borutzki, Isabel Herbert, Stefanie Hochmuth and Monkia Marunde for excellent technical assistance. We also acknowledge the support and advise of Dr. Anja Oelschlegel in all animal experiments.

\section{Authors' contributions}

$A C, E C, M R A, S J, G M G, P Y, R R, T L, A K$ and KMG performed experiments. AC, EC, MRA, SJ, GG, PY, TL, AK, RA, AD and MRK analyzed and interpreted data. AC, EC, KMG, AK and GMG generated figures/tables. AS, RA, AD and MRK provided material, technology and funding. MRK designed the study and wrote the paper. AC, EC, AK and MRK prepared the manuscript. All authors provided critical insight and review of the manuscript. All authors read and approved the final manuscript.

\section{Funding}

Open Access funding enabled and organized by Projekt DEAL. Supported by Grants from the Deutsche Forschungsgemeinschaft (DFG) (Kr 1879/9-1/ FOR 2419, Kr1879/5-1/6-1/10-1; CRC1436 A02 Project-ID 425899996; Research Training Group 2413 SynAGE, TP4), BMBF 'Energi'FKZ: 01GQ1421B, The EU Joint Programme-Neurodegenerative Disease Research (JPND) project STAD (01ED1613) and Leibniz Foundation SAW 'ISAS2', 'SynMetAge',
'Neurotranslation'and 'SynErca' to MRK.; CRC1436 A02 Project-ID 425899996 to AK; CRC1436 A05 Project-ID 425899996, Research Training Group 2413 SynAGE TP5 and BMBF 'Energi' FKZ: 01GQ1421A to AD. G.M.G. was supported by the Alexander-von-Humboldt Foundation/CAPES post-doctoral research fellowship (99999.001756/2014-01).

Availability of data and materials

All data generated or analyzed during this study are included in this published article and its Additional file 1.

\section{Declarations}

Ethics approval and consent to participate

Not applicable.

Consent for publication

Not applicable.

\section{Competing interests}

The authors declare that they have no competing interests.

\section{Author details}

${ }^{1}$ RG Neuroplasticity, Leibniz-Institute for Neurobiology, 39118 Magdeburg, Germany. ${ }^{2}$ German Center for Neurodegenerative Diseases (DZNE), 39120 Magdeburg, Germany. ${ }^{3}$ Center for Behavioral Brain Sciences, Otto Von Guericke University, 39120 Magdeburg, Germany. ${ }^{4}$ Leibniz-Institut Für Analytische Wissenschaften-ISAS-e.V., 44227 Dortmund, Germany. ${ }^{5}$ Leibniz Group 'Dendritic Organelles and Synaptic Function', Center for Molecular Neurobiology, ZMNH, University Medical Center Hamburg-Eppendorf, 20251 Hamburg, Germany. ${ }^{6}$ Department of Analytical Chemistry, Faculty of Chemistry, University of Vienna, 1090 Wien, Austria. ${ }^{7}$ Medical Faculty, Otto-von-Guericke University, 39120 Magdeburg, Germany.

Received: 17 September 2021 Accepted: 24 December 2021

Published online: 06 January 2022

\section{References}

1. Blüher M. Obesity: global epidemiology and pathogenesis. Nat Rev Endocrinol. 2019;15:288-98.

2. Leibson CL, Rocca WA, Hanson VA, Cha R, Kokmen E, O'Brien PC, et al. Risk of dementia among persons with diabetes mellitus: a population-based cohort study. Am J Epidemiol. 1997:145:301-8.

3. Biessels GJ, Staekenborg S, Brunner E, Brayne C, Scheltens P. Risk of dementia in diabetes mellitus: a systematic review. Lancet Neurol. 2006;5:64-74.

4. Barbagallo M, Dominguez $L J$. Type 2 diabetes mellitus and Alzheimer's disease. World J Diabetes. 2014;5:889-93.

5. Huang Y, Mahley RW. Apolipoprotein E: structure and function in lipid metabolism, neurobiology, and Alzheimer's diseases. Neurobiol Dis. 2014;72:3-12.

6. Li L, Cao Y, Wu H, Ye X, Zhu Z, Xing G, et al. Enzymatic activity of the scaffold protein rapsyn for synapse formation. Neuron. 2016;92:1007-19.

7. Yaffe K, Kanaya A, Lindquist K, Simonsick EM, Harris T, Shorr RI, et al. The metabolic syndrome, inflammation, and risk of cognitive decline. JAMA. 2004:292:2237-42.

8. Awad N, Gagnon M, Messier C. The relationship between impaired glucose tolerance, type 2 diabetes, and cognitive function. J Clin Exp Neuropsychol. 2004;26:1044-80.

9. Kim B, Feldman EL. Insulin resistance as a key link for the increased risk of cognitive impairment in the metabolic syndrome. Exp Mol Med. 2015;47:e149-e149.

10. Chatterjee S, Mudher A. Alzheimer's disease and type 2 diabetes: a critical assessment of the shared pathological traits. Front Neurosci. 2018;12:383.

11. Więckowska-Gacek A, Mietelska-Porowska A, Chutorański D, Wydrych M, Długosz J, Wojda U. Western diet induces impairment of liver-brain axis accelerating neuroinflammation and amyloid pathology in Alzheimer's disease. Front Aging Neurosci. 2021;13:654509. 
12. Vanhanen M, Koivisto K, Moilanen L, Helkala EL, Hänninen T, Soininen $\mathrm{H}$, et al. Association of metabolic syndrome with Alzheimer disease: a population-based study. Neurology. 2006;67:843-7.

13. Biessels GJ, Reagan LP. Hippocampal insulin resistance and cognitive dysfunction. Nat Rev Neurosci. 2015;16:660-71.

14. Guillemot-Legris $O$, Muccioli GG. Obesity-induced neuroinflammation: beyond the hypothalamus. Trends Neurosci. 2017;40:237-53.

15. Kuljiš RO, Salković-Petrišić M. Dementia, diabetes, Alzheimer's disease, and insulin resistance in the brain: progress, dilemmas, new opportunities, and a hypothesis to tackle intersecting epidemics. J Alzheimers Dis. 2011;25:29-41.

16. Frisardi V, Solfrizzi V, Seripa D, Capurso C, Santamato A, Sancarlo D, et al. Metabolic-cognitive syndrome: a cross-talk between metabolic syndrome and Alzheimer's disease. Ageing Res Rev. 2010;9:399-417.

17. De Felice FG, Lourenco MV, Ferreira ST. How does brain insulin resistance develop in Alzheimer's disease? Alzheimers Dement. 2014;10:S26-32.

18. Lyra e Silva NDM, Gonçalves RA, Boehnke SE, Forny-Germano L, Munoz DP, De Felice FG. Understanding the link between insulin resistance and Alzheimer's disease: insights from animal models. Exp Neurol. 2019:316:1-11.

19. Kellar D, Craft S. Brain insulin resistance in Alzheimer's disease and related disorders: mechanisms and therapeutic approaches. Lancet Neurol. 2020;19:758-66.

20. Heneka MT, Carson MJ, El Khoury J, Landreth GE, Brosseron F, Feinstein $\mathrm{DL}$, et al. Neuroinflammation in Alzheimer's disease. Lancet Neurol. 2015;14:388-405

21. Newcombe EA, Camats-Perna J, Silva ML, Valmas N, Huat TJ, Medeiros R. Inflammation: the link between comorbidities, genetics, and Alzheimer's disease. J Neuroinflamm. 2018;15:276.

22. Cline EN, Bicca MA, Viola KL, Klein WL. The amyloid- $\beta$ oligomer hypothesis: beginning of the third decade. J Alzheimers Dis. 2018:64:567-610.

23. Grochowska KM, Yuanxiang P, Bär J, Raman R, Brugal G, Sahu G, et al. Posttranslational modification impact on the mechanism by which amyloid- $\beta$ induces synaptic dysfunction. EMBO Rep. 2017;18:962-81.

24. Kendig MD, Leigh SJ, Morris MJ. Unravelling the impacts of western-style diets on brain, gut microbiota and cognition. Neurosci Biobehav Rev. 2021;128:233-43.

25. Melo HM, Santos LE, Ferreira ST. Diet-derived fatty acids, brain inflammation, and mental health. Front Neurosci. 2019;13:265

26. Karpova A, Mikhaylova M, Bera S, Bär J, Reddy PP, Behnisch T, et al. Encoding and transducing the synaptic or extrasynaptic origin of NMDA receptor signals to the nucleus. Cell. 2013;152:1119-33.

27. Alexandru A, Jagla W, Graubner S, Becker A, Bauscher C, Kohlmann S, et al. Selective hippocampal neurodegeneration in transgenic mice expressing small amounts of truncated $A$ is induced by pyroglutamate-a formation. J Neurosci. 2011;31:12790-801.

28. Behnisch T, YuanXiang P, Bethge P, Parvez S, Chen Y, Yu J, et al. Nuclear translocation of Jacob in hippocampal neurons after stimuli inducing long-term potentiation but not long-term depression. PLoS One. 2011;6:e17276.

29. Yuanxiang P, Bera S, Karpova A, Kreutz MR, Mikhaylova M. Isolation of CA1 nuclear enriched fractions from hippocampal slices to study activitydependent nuclear import of synapto-nuclear messenger proteins. J Vis Exp. 2014;e51310.

30. Andres-Alonso M, Ammar MR, Butnaru I, Gomes GM, Acuña Sanhueza G, Raman R, et al. SIPA1L2 controls trafficking and local signaling of TrkB-containing amphisomes at presynaptic terminals. Nat Commun. 2019;10:5448

31. Dieterich DC, Karpova A, Mikhaylova M, Zdobnova I, König I, Landwehr $M$, et al. Caldendrin-Jacob: a protein liaison that couples NMDA receptor signalling to the nucleus. PLoS Biol. 2008;6:e34

32. Wendholt D, Spilker C, Schmitt A, Dolnik A, Smalla KH, Proepper C, et al. ProSAP-interacting Protein 1 (ProSAPiP1), a novel protein of the postsynaptic density that links the spine-associated Rap-Gap (SPAR) to the scaffolding protein ProSAP2/Shank3. J Biol Chem. 2006;281:13805-16.

33. Spilker C, Nullmeier S, Grochowska KM, Schumacher A, Butnaru I, Macharadze T, et al. A Jacob/Nsmf gene knockout results in hippocampal dysplasia and impaired BDNF signaling in dendritogenesis. PLOS Genet. 2016:12:e1005907.
34. Tsuriel S, Geva R, Zamorano P, Dresbach T, Boeckers T, Gundelfinger ED, et al. Local sharing as a predominant determinant of synaptic matrix molecular dynamics. PLoS Biol. 2006:4:e271.

35. Bomfim TR, Forny-Germano L, Sathler LB, Brito-Moreira J, Houzel J-C, Decker $\mathrm{H}$, et al. An anti-diabetes agent protects the mouse brain from defective insulin signaling caused by Alzheimer's disease-associated A $\beta$ oligomers. J Clin Invest. 2012;122(4):1339-53.

36. De Felice FG. Alzheimer's disease and insulin resistance: translating basic science into clinical applications. J Clin Invest. 2013;123:531-9.

37. Saido TC, Iwatsubo T, Mann DM, Shimada H, Ihara Y, Kawashima S. Dominant and differential deposition of distinct beta-amyloid peptide species, A beta N3(pE), in senile plaques. Neuron. 1995;14:457-66.

38. Harigaya Y, Saido TC, Eckman CB, Prada CM, Shoji M, Younkin SG. Amyloid $\beta$ protein starting pyroglutamate at position 3 is a major component of the amyloid deposits in the Alzheimer's disease brain. Biochem Biophys Res Commun. 2000;276:422-7.

39. Bayer TA, Wirths O. Focusing the amyloid cascade hypothesis on $\mathrm{N}$-truncated Abeta peptides as drug targets against Alzheimer's disease. Acta Neuropathol. 2014;127:787-801.

40. Nussbaum JM, Schilling S, Cynis H, Silva A, Swanson E, Wangsanut T, et al. Prion-like behavior and tau-dependent cytotoxicity of pyroglutamylated B-amyloid. Nature. 2012;485:651-5.

41. Boucher J, Kleinridders A, Kahn CR. Insulin receptor signaling in normal and insulin-resistant states. Cold Spring Harb Perspect Biol. 2014:6:a009191.

42. Gual P, Le Marchand-Brustel Y, Tanti JF. Positive and negative regulation of insulin signaling through IRS-1 phosphorylation. Biochimie. 2005;87:99-109.

43. Mayer CM, Belsham DD. Central insulin signaling is attenuated by longterm insulin exposure via insulin receptor substrate-1 serine phosphorylation, proteasomal degradation, and lysosomal insulin receptor degradation. Endocrinology. 2010;151:75-84.

44. Yarchoan M, Toledo JB, Lee EB, Arvanitakis Z, Kazi H, Han LY, et al. Abnormal serine phosphorylation of insulin receptor substrate 1 is associated with tau pathology in Alzheimer's disease and tauopathies. Acta Neuropathol. 2014:128:679-89.

45. Tamemoto H, Kadowaki T, Tobe K, Yagi T, Sakura H, Hayakawa T, et al. Insulin resistance and growth retardation in mice lacking insulin receptor substrate-1. Nature. 1994;372:182-6

46. Zhande R, Mitchell JJ, Wu J, Sun XJ. Molecular mechanism of insulininduced degradation of insulin receptor substrate 1. Mol Cell Biol. 2002:22:1016-26.

47. Manning BD, Cantley LC. AKT/PKB signaling: navigating downstream. Cell. 2007:129:1261-74

48. Hers I, Vincent EE, Tavaré JM. Akt signalling in health and disease. Cell Signal. 2011;23:1515-27.

49. Ebner M, Lučić I, Leonard TA, Yudushkin I. PI(3,4,5)P3 engagement restricts akt activity to cellular membranes. Mol Cell. 2017;65:416-431.e6.

50. Kim J-I, Lee H-R, Sim S, Baek J, Yu N-K, Choi JH, et al. PI3Ky is required for NMDA receptor-dependent long-term depression and behavioral flexibility. Nat Neurosci. 2011;14:1447-54.

51. Xu X, Sarikas A, Dias-Santagata DC, Dolios G, Lafontant PJ, Tsai SC, et al. The CUL7 E3 ubiquitin ligase targets insulin receptor substrate 1 for ubiquitin-dependent degradation. Mol Cell. 2008;30:403-14.

52. Xu X, Keshwani M, Meyer K, Sarikas A, Taylor S, Pan ZQ. Identification of the degradation determinants of insulin receptor substrate 1 for signaling Cullin-RING E3 ubiquitin ligase 7-mediated ubiquitination. J Biol Chem. 2012;287:40758-66.

53. Enchev RI, Schulman BA, Peter M. Protein neddylation: beyond cullinRING ligases. Nat Rev Mol Cell Biol. 2015;16:30-44.

54. Soucy TA, Smith PG, Milhollen MA, Berger AJ, Gavin JM, Adhikari S, et al. An inhibitor of NEDD8-activating enzyme as a new approach to treat cancer. Nature. 2009;458:732-6.

55. Casas C, Sergeant N, Itier JM, Blanchard V, Wirths O, van der Kolk N, et al. Massive CA1/2 neuronal loss with intraneuronal and $\mathrm{N}$-terminal truncated $A \beta 42$ accumulation in a novel Alzheimer transgenic model. Am J Pathol. 2004;165:1289-300

56. Labouèbe G, Liu S, Dias C, Zou H, Wong JCY, Karunakaran S, et al. Insulin induces long-term depression of ventral tegmental area dopamine neurons via endocannabinoids. Nat Neurosci. 2013;16:300-8. 
57. Assini FL, Duzzioni M, Takahashi RN. Object location memory in mice: pharmacological validation and further evidence of hippocampal CA1 participation. Behav Brain Res. 2009;204:206-11.

58. Haettig J, Sun Y, Wood MA, Xu X. Cell-type specific inactivation of hippocampal CA1 disrupts location-dependent object recognition in the mouse. Learn Mem. 2013;20:139-46.

59. Vogl AM, Brockmann MM, Giusti SA, Maccarrone G, Vercelli CA, Bauder CA, et al. Neddylation inhibition impairs spine development, destabilizes synapses and deteriorates cognition. Nat Neurosci. 2015;18:239-51.

60. Brockmann MM, Döngi M, Einsfelder U, Körber N, Refojo D, Stein V. Neddylation regulates excitatory synaptic transmission and plasticity. Sci Rep. 2019:9:1-10.

61. Bayraktar G. Synaptic control of DNA methylation involves activitydependent degradation of DNMT3A1 in the nucleus. Neuropsychopharmacology. 2020;45:2120-30.

62. Patrón LA, Nagatomo K, Eves DT, Imad M, Young K, Torvund M, et al. Cul4 ubiquitin ligase cofactor DCAF12 promotes neurotransmitter release and homeostatic plasticity. J Cell Biol. 2019;218:993-1010.

63. Xiong C, Zhou L, Tan J, Song S, Bao X, Zhang N, et al. Development of potent NEDD8-activating enzyme inhibitors bearing a pyrimidotriazole scaffold. J Med Chem. 2021;64:6161-78.

64. Vogl AM, Phu L, Becerra R, Giusti SA, Verschueren E, Hinkle TB, et al. Global site-specific neddylation profiling reveals that NEDDylated cofilin regulates actin dynamics. Nat Struct Mol Biol. 2020;27:210-20.

65. Scudder SL, Patrick GN. Synaptic structure and function are altered by the neddylation inhibitor MLN4924. Mol Cell Neurosci. 2015;65:52-7.

66. Bhaskar K, Maphis N, Xu G, Varvel NH, Kokiko-Cochran ON, Weick JP, et al. Microglial derived tumor necrosis factor-a drives Alzheimer's diseaserelated neuronal cell cycle events. Neurobiol Dis. 2014;62:273-85.

67. Ma QL, Yang F, Rosario ER, Ubeda OJ, Beech W, Gant DJ, et al. $\beta$-amyloid oligomers induce phosphorylation of tau and inactivation of insulin receptor substrate via c-Jun $\mathrm{N}$-terminal kinase signaling: suppression by omega-3 fatty acids and curcumin. J Neurosci. 2009;29:9078-89.

68. Talbot K, Wang HY, Kazi H, Han LY, Bakshi KP, Stucky A, et al. Demonstrated brain insulin resistance in Alzheimer's disease patients is associated with IGF-1 resistance, IRS-1 dysregulation, and cognitive decline. J Clin Invest. 2012;122:1316-38.

69. Mullins RJ, Diehl TC, Chia CW, Kapogiannis D. Insulin resistance as a link between amyloid-beta and tau pathologies in Alzheimer's disease. Front Aging Neurosci. 2017;9:118.

70. Hugon J, Mouton-Liger F, Dumurgier J, Paquet C. PKR involvement in Alzheimer's disease. Alzheimers Res Ther. 2017;9:83.

71. Lourenco MV, Clarke JR, Frozza RL, Bomfim TR, Forny-Germano L, Batista AF, et al. TNF-a mediates PKR-dependent memory impairment and brain IRS-1 inhibition induced by Alzheimer's $\beta$-amyloid oligomers in mice and monkeys. Cell Metab. 2013;18:831-43.

72. Tible M, Mouton Liger F, Schmitt J, Giralt A, Farid K, Thomasseau S, et al. PKR knockout in the 5xFAD model of Alzheimer's disease reveals beneficial effects on spatial memory and brain lesions. Aging Cell. 2019;18:e12887

Ready to submit your research? Choose BMC and benefit from:

- fast, convenient online submission

- thorough peer review by experienced researchers in your field

- rapid publication on acceptance

- support for research data, including large and complex data types

- gold Open Access which fosters wider collaboration and increased citations

- maximum visibility for your research: over $100 \mathrm{M}$ website views per year

At BMC, research is always in progress.

Learn more biomedcentral.com/submissions 